IZA DP No. 6994

New Estimates of the Value of a Statistical Life Using Air Bag Regulations as a Quasi-Experiment

Chris Rohlfs

Ryan Sullivan

Thomas J. Kniesner

November 2012 


\title{
New Estimates of the Value of a Statistical Life Using Air Bag Regulations as a Quasi-Experiment
}

\author{
Chris Rohlfs \\ Syracuse University \\ Ryan Sullivan \\ Naval Postgraduate School \\ Thomas J. Kniesner \\ Syracuse University, \\ Claremont Graduate University and IZA
}

\author{
Discussion Paper No. 6994 \\ November 2012
}

\author{
IZA \\ P.O. Box 7240 \\ 53072 Bonn \\ Germany \\ Phone: +49-228-3894-0 \\ Fax: +49-228-3894-180 \\ E-mail: iza@iza.org
}

\begin{abstract}
Any opinions expressed here are those of the author(s) and not those of IZA. Research published in this series may include views on policy, but the institute itself takes no institutional policy positions. The IZA research network is committed to the IZA Guiding Principles of Research Integrity.

The Institute for the Study of Labor (IZA) in Bonn is a local and virtual international research center and a place of communication between science, politics and business. IZA is an independent nonprofit organization supported by Deutsche Post Foundation. The center is associated with the University of Bonn and offers a stimulating research environment through its international network, workshops and conferences, data service, project support, research visits and doctoral program. IZA engages in (i) original and internationally competitive research in all fields of labor economics, (ii) development of policy concepts, and (iii) dissemination of research results and concepts to the interested public.
\end{abstract}

IZA Discussion Papers often represent preliminary work and are circulated to encourage discussion. Citation of such a paper should account for its provisional character. A revised version may be available directly from the author. 
IZA Discussion Paper No. 6994

November 2012

\section{ABSTRACT}

\section{New Estimates of the Value of a Statistical Life Using Air Bag Regulations as a Quasi-Experiment}

Due to Federal regulations, automobile air bag availability was a model-specific discontinuous function of model year for used vehicles in the 1990s and early 2000s. We use these discontinuities and the gradual increase in the supply of air bags to trace out the demand curve for air bags and the implied distribution of the Value of a Statistical Life (VSL) across consumers. While imprecise, our preferred point estimates indicate that the median VSL is between $\$ 7$ million and $\$ 13$ million, but that a sizable portion of consumers placed negative values on air bags, probably due to distrust of the technology.

JEL Classification: J17, R41, I18, K32, L62, D12, D61, H40

Keywords: value of statistical life, VSL, airbags, regression discontinuity design, quasi-experiment

Corresponding author:

Thomas J. Kniesner

Center for Policy Research

426 Eggers Hall

Syracuse University

Syracuse, NY 13244

USA

E-mail: tkniesne@maxwell.syr.edu

\footnotetext{
* This project was made possible through generous support from National Institute of Aging (NIA) grant number 1 R03 AG 031371-01A2. We are grateful for expert research assistance from Min-Fang Rae Lan and for helpful comments from Bill Dougan, Jeff Kubik, and anonymous NIA referees.
} 
The Value of a Statistical Life (VSL), conceived by Thaler and Rosen (1975), is one of the most important and frequently cited parameters that economists estimate. A large literature exists on the VSL, and VSL estimates based upon wage and automobile price regressions and contingent valuation surveys are used by many government agencies, including the Department of Transportation, the Environmental Protection Agency, and the National Institutes of Health, to evaluate the cost-effectiveness of policies that extend people's lives or reduce the risk of fatalities (Holt, 2003; Viscusi, 1996). This paper develops new estimates of the VSL and how it varies across individuals using a quasi-experimental research design based upon regulations in the 1990s requiring air bags in automobiles.

Considerable disagreement exists in the literature as to what the "true" VSL is. The dominant estimates range from $\$ 5.0$ million to $\$ 11.7$ million in 2010 dollars and come from Viscusi's (1993) meta-analysis of OLS estimates of the VSL. ${ }^{2}$ That study focuses primarily upon labor market VSL estimates that are obtained from OLS regressions of wages on job-specific fatality risk. VSL estimates from OLS regressions of automobile prices on safety devices such as air bags and obtain similar ranges of estimates (Atkinson and Halvorsen, 1990; de Blaeij, et al., 2003; Dionne and Lanoie, 2004; Dreyfus and Viscusi, 1995; Mount, et al., 2004). More recent associational evidence has found that the VSL rises over time with economic growth, so that the VSL today is higher than the range found in Viscusi's earlier study (Viscusi and Aldy, 2003; Costa and Kahn, 2004). In a recent and controversial move, the EPA in 2008 lowered the VSL that it uses for cost-benefit analyses, a decision that was driven in part another recent metaanalysis of OLS regressions of wages on fatality risk (Akre, 2008; Borenstein, 2008). That study found that the VSL ranges from \$2.0 million to \$3.3 million (Mrozek and Taylor, 2002).

\footnotetext{
${ }^{2}$ All dollar values in this paper are converted to 2010 dollars.
} 
Some recent researchers have argued that OLS methods for estimating the VSL suffer from important biases driven by omitted determinants of wages or car prices that are correlated with safety, the use of non-representative populations, and imprecision in measures of fatality risk (Ashenfelter, 2006; Ashenfelter and Greenstone, 2004a; Black and Kniesner, 2003). To address the problem of omitted variables bias, some recent studies use fixed effects regressions and focus on workers who changed between safe and risky jobs; these studies have produced mixed results. One such study finds VSL estimates ranging from \$6.5 million to \$8.2 million (Kniesner, Viscusi, Woock, and Ziliak, 2012), and another such study finds negative VSLs (Hintermann, Alberini, and Markandya, 2006). By controlling for fixed determinants of worker productivity, these studies help to address the omitted variables problems. However, a small fraction of Americans work in risky jobs, and workers in risky jobs are likely to have very different VSLs than the typical American does. Additionally, the occupation- and industryspecific measures of job-specific fatality risk are imprecise estimates of the risks that individual workers face, and adding fixed effects to the wage regressions is likely to exacerbate any measurement error bias (Griliches, 1979). ${ }^{3}$

There is very little evidence on the VSL that does not suffer from these substantial biases. Two recent quasi-experimental studies seems to support Mrozek and Taylor's (2002) finding that the VSL is smaller than the dominant estimates suggest; however, those studies also suffer from important biases. Ashenfelter and Greenstone (2004b) examine state politicians’ decisions to adopt a Federal speed limit change. They examine tradeoffs between the fatality risks versus the time savings (valued at the average wage) of higher speeds. The authors assume that the median voter determined politicians’ decisions, and they estimate that this median voter’s VSL was \$2.1

\footnotetext{
${ }^{3}$ Additionally, the fixed effects estimates are subject to biases due to any omitted health-, family-, or productivityrelated factors that influence the decision to change into or out of a risky job.
} 
million. Schnier, Horrace, and Felthoven (2009) examine daily decisions made by Alaskan crab boat captains on whether or not to take out their boats. The authors estimate a structural model that exploits exogenous variation in weather (which increases fatality risk) and catch limits (which reduce the monetary benefits per day of fishing). Using these tradeoffs, the authors obtain somewhat unstable VSL estimates ranging from $-\$ 1.2$ million to $+\$ 2.2$ million. ${ }^{4}$ These two studies make important contributions to the literature in that they are the only studies that use exogenous changes in risk to estimate this important parameter, and they avoid many of the omitted variables biases associated with previous estimates; however, both have key limitations. Ashenfelter and Greenstone heavily upon the median voter theorem, and there is no evidence to suggest that the politicians' decisions reflected the preferences of typical residents of their states. ${ }^{5}$ As Schnier, Horrace, and Felthoven note, crab fishing was the riskiest profession in the country at the time of their study, and those VSL estimates apply to a highly non-representative population of workers. Additionally, the weather and catch limit policies that Schnier, Horrace, and Felthoven examine are likely to have affected the decision to fish for reasons other than risk and dollars. Inclement weather negatively affects the comfort of the job, and catch limit policies reduce the amount of effort required in a given workday. ${ }^{6}$

The current paper is the first to provide VSL estimates based upon exogenous shocks to risks faced by typical consumers. Obtaining such estimates is particularly important, because

\footnotetext{
${ }^{4}$ The estimates reported here are the estimates of the captain's valuation of his own life. The main estimates reported by the authors are somewhat higher than these estimates, ranging from $\$ 4.2$ million to $\$ 5.0$ million. Those main specifications assume that the captain valued each crew member's life equally to his own.

${ }^{5}$ It is also not clear that the politicians had accurate estimates of the effects of the speed limits on fatality risk.

${ }^{6}$ Another limitation with the crab fishing study is that the authors use a combination of nonlinear functional forms, and it is not clear that the exogenous shocks are driving the findings. In addition to these papers, a recent quasiexperimental study by Rohlfs (2011) measures the effect of exogenous shocks to the risk of being drafted into the Vietnam War on draft avoidance behaviors. Because fatality risk was only one of the reasons for avoiding the draft, that study obtains an upper bound on the VSL for young men. That upper bound, which ranges from \$7 million to $\$ 12$ million, is relatively low, which suggests that the VSL may be lower than predominant estimates. However, the average American is probably more averse to fatality risk than was a 19-year-old man in the 1960s.
} 
policymakers are changing the VSLs that they use based upon recent estimates that might not be accurate. For every vehicle model produced continuously through the 1990s, the early model years had no air bags, and the later model years had both driver's and passenger’s side air bags. For each model, air bag availability is a discontinuous function of model year. After restricting the sample to the model years just before and just after air bags were made available, air bag availability is found to be generally uncorrelated with other design features and owner characteristics. This discontinuity approach provides exogenous variation in risk in a real market, thus addressing the problem of omitted variables bias.

In the earlier years of the 1990s when air bags were rare, the hedonic price of an air bag was determined by buyers with relatively high marginal willingness to pay (MWTP) for the technology. As air bags became more common, buyers with the greatest demand for air bags became inframarginal, and the price decreased. By measuring the price of an air bag over the multiple years of this increase in the supply of air bags, we trace out the demand curve for air bags and the implied distribution of VSLs across American car owners, thus addressing the problem of identifying the VSL for the appropriate population.

The data compiled for this study are some of the most extensive automobile data that have been used in the economics literature. Used automobile price data were purchased from two industry sources, and the numbers of registered vehicles were purchased from a third industry source. All of these data include separate information for each make, model, model year, and year of observation. Additional public sources are used to measure air bag availability, other vehicle features, consumer demographics, and fatality rates. The use of nationwide data on all vehicle-related deaths and the ability to estimate separate risk measures by vehicle model and demographic group helps to address the problem of measurement error. Estimates of the effects 
of air bags were widely available on television and in the popular press. Additionally, unlike with job choices, safety features and the risk of death are highly salient issues that typically factor into automobile purchase decisions.

Driver's side and passenger's side air bags are found to have reduced the risk of death in a vehicle by roughly 20 per million and 4 per million per year that the vehicle was driven. In 1991, the point estimate for the premium on a driver's side air bag is estimated to have been between $\$ 2,000$ and $\$ 8,000$ in 2010 dollars, and the point estimate for the premium on a (relatively rare) passenger’s side air bag is estimated to have been between $\$ 5,000$ and $\$ 8,000$. These premiums are estimated to have declined at a rate of $\$ 300$ to $\$ 1,100$ per year and became negative in the early 2000s, possibly due to suspicions by some that the technology increased fatality risk.

In the main specifications, the point estimates of the VSLs implied by the hedonic prices on driver's side air bags range from $\$ 7.8$ million to $\$ 18.5$ million at the $75^{\text {th }}$ percentile of the MWTP distribution, $\$ 6.6$ million to $\$ 13.0$ million at the $50^{\text {th }}$ percentile, and $-\$ 9.6$ million to $+\$ 2.9$ million at the $25^{\text {th }}$ percentile. The VSL estimates for the median car buyer are higher than previous studies find and suggest that the recent policy to reduce the official VSL was misguided. The VSLs implied by the prices on passengers' air bags vary more widely due to the smaller effects of passenger's side air bags on fatalities; the estimates are somewhat sensitive to the specification used. VSL values for whites and Asians are found to be similar to those for other races, and at the higher end of the VSL distribution, car buyers who are 60 and older appear to value risk reductions slightly more than younger car buyers do. We find suggestive evidence of a positive relationship between median VSL and median income in a state. 


\section{Key institutional factors}

\section{A. Regulations and air bag availability}

The automobile air bag was invented in the early 1950s as a means of protecting drivers and passengers when serious accidents occur. Driver's side versions were first introduced into some models of consumer automobiles in the mid-1970s (Bellis, 2005). Government requirements for air bags began in the 1980s, when the 1984 amendments to the Federal Motor Vehicle Safety Standard 208 (FMVSS 208, U.S. Department of Transportation, 1985, 2005) stated that, by the 1990 model year, all new cars produced for sale in the U.S. must have a “passive restraint” - either a driver’s side air bag or automatic safety belts. ${ }^{7}$ Federal regulations became more stringent in 1991, with the passage of the Intermodal Surface Transportation Efficiency Act (ISTEA, U.S. $102^{\text {nd }}$ Congress, 1991), which required that all new cars sold in the U.S. have driver's side air bags by model year 1996 and passenger's side air bags by model year 1997. The law also required new light trucks and SUVs to have driver’s side air bags by 1997 and passenger’s side air bags by 1998.

The prevalence of drivers' and passenger' side automobile air bags over time is shown in Figure 1. Models either include air bags as standard or not at all; no vehicles had optional air bags. Panel A shows the fraction of new vehicles that were sold in the U.S. that included air bags, plotted by model year. The solid and dashed black curves show the fractions of car models that included the driver's and the passenger's side air bags. The solid and dashed gray curves show the same fractions for light trucks and SUVs. Panel B shows the same fractions for new

\footnotetext{
${ }^{7}$ FMVSS 208 also mandated a phase-in schedule that specified the fractions of each manufacturer's vehicles that had to meet the standard in the years preceding the deadlines. A similar FMVSS 208 regulation applied to light trucks and sport utility vehicles (SUVs) with a later deadline of 1998 for full compliance; however, that regulation was superseded by the earlier ISTEA air bags deadlines.
} 
and used vehicles purchased in the U.S. by observation year; panel C shows these fractions for all registered vehicles (new and used) in the U.S., plotted by observation year.

As all four curves in Panel a show, use of air bags was rare until the FMVSS 208 regulation became effective in 1990. After 1990, all four fractions increase sharply until reaching 100\% at their respective 1996, 1997, and 1998 deadlines. In practice, the phase-in schedules and deadlines for total compliance were not binding for many auto manufacturers. While automatic seatbelts remained an option until the 1996, 1997, and 1998 deadlines, focus group results consistently shows that consumers strongly preferred air bags (Kramer, 1979). Nevertheless, due to the high costs of production, air bags were primarily restricted to luxury cars until 1988 , when Chrysler announced that it would phase in air bags for its entire fleet by 1990, a decision that it reported was primarily driven by regulations (Holusha, 1990). The models for which air bags were adopted prior to the deadlines tended to be higher end vehicles (due to higher demand for air bags in higher end vehicles) and vehicles with higher production volume (due to diminishing marginal costs). Ford and General Motors lagged behind Chrysler, claiming that consumers were not willing to pay the higher costs (Doron, 1990; Law, 1992). The Japanese manufacturers (who tended to target a lower-end market) lagged further behind (Kurlko, 1989).

Panels B and C show steady increases in the fractions of purchased and registered vehicles with air bags over the entire sample period. The increases are slower and later than those seen in panel A due to the gradual introduction of newer automobiles into the population of vehicles. Hence, while $100 \%$ of vehicles produced in 1998 and later had dual air bags, the corresponding fractions were only $60.8 \%$ of cars and $48.6 \%$ of light trucks and SUVs sold that year. By 2005, the latest year in the sample, $66.5 \%$ of cars and $64.2 \%$ of light trucks and SUVs that were registered had dual air bags. 


\section{B. Public perceptions of air bags}

Estimates of the air bags’ effectiveness have been available and widely publicized for many years. From 1990 to 2000, 318 articles in The New York Times, Newsweek, and USA Today mention both "air bags" and "risk” (Lexis Nexus, 2007). The estimates of air bags' effects that appear in these articles are framed in a variety of ways, including "air bags ... .[reduce] the risk of death in head-on collisions by 26 percent and in all serious accidents by 13 percent” (Meier, New York Times, 1992), and “air bags . . . are credited with saving 1,136 people from 1986 through 1995” (O’Donnell, USA Today, 1996). Many of these articles provide separate estimates by age, sex, or whether the driver wore a seatbelt, and many also include related statistics such as the overall risk of automobile-related death or comparisons between the effects of air bags and those of seatbelts.

Public attitudes toward air bags appear to have been fairly stable over the past few decades, but with some key changes. In 1978, 58\% of Americans supported efforts to make automatic seatbelts or air bags mandatory (Kramer, 1978). In 1984, 60\% favored and 31\% opposed regulations requiring air bags in all cars (New York Times, 1984). Over the 1990s, as air bags became more common and Chrysler launched a high-profile advertising campaign, some changes occurred in public perceptions about the value of the technology. Between 1990 and 1992, the fraction of consumers who reported being willing to pay an additional $\$ 500$ for an air bag (roughly \$800 in 2010 dollars) increased from 29\% to 44\% (Hinsberg, 1992; Sawyers, 1990).

In 1996 and 1997, new information became available and publicized on the risks of air bags to young children and shorter drivers; this information appears to have reduced support for 
air bags (Nelson, Sussman, and Graham, 1999; O’Donnell, 1996; Ottaway, 1996). In 1997, 58.0\% reported that their views about air bags were about the same as they were three years before, $26.0 \%$ reported that their views had become less favorable, and $18.8 \%$ reported that their views had become more favorable (Nelson, Sussman, and Graham, 1999). By 1997, support for mandatory air bags was slightly higher than it had been in 1984, with $66.3 \%$ favoring the policy and $29.4 \%$ opposing it.

A national survey conducted in 1998 and 1999 by Corso, Hammitt, and Graham (2001) found that $45 \%$ of American adults believe that air bags are "very effective,” while only 1\% rated them as "not at all effective." When rating the likelihood of death in an automobile accident, $41 \%$ believed that they had lower than average risk, $42 \%$ believed that they had average risk, and $17 \%$ believed that they had higher than average risk.

\section{Conceptual framework}

\section{$\underline{\text { A. Effects of air bags on prices and fatalities }}$}

Let $P_{i y t}$ denote the year $t$ price of automobile model $i$ from model year $y$, and let $F_{i y}^{p}$ denote the rate of deaths in position $p$ (driver's or passenger's side) per vehicle in a typical year for model $i$ from model year $y$. Let Airbag $_{i y}^{\text {Driver }}$ and Airbag $_{i y}^{\text {Psngr }}$ be indicator variables for whether model $i$ automobiles included air bags in the driver's and passenger's side production year $y$. A given automobile's fatality rate and price can be described by the following equations:

1) $F_{\text {piy }}=\phi_{p}^{\text {Driver }} * A i r b a g_{i y}^{\text {Driver }}+\phi_{p}^{\text {Psngr }} * A i r b a g_{i y}^{\text {Psngr }}+\mathbf{x}_{\mathbf{1 i y}}^{\prime} \boldsymbol{\delta}_{\mathbf{p}}+u_{\text {piy }}$, and

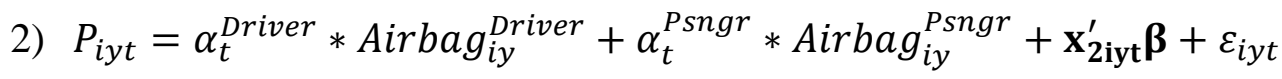


The parameters $\phi_{p}^{\text {Driver }}$ and $\phi_{p}^{\text {Psngr }}$ represent the effects of drivers' and passengers' side air bags on a vehicle's annual rate of fatalities in position $p$. Both $\phi_{\text {Driver }}^{\text {Driver }}$ and $\phi_{P s n g r}^{P s n g r}$ are predicted to be negative, so that having an air bag in a given position reduces fatalities among those seated in that position. The parameters $\alpha_{t}^{\text {Driver }}$ and $\alpha_{t}^{\text {Psngr }}$ represent the increases in automobile prices associated with driver's side and passenger's side air bags, respectively. The $t$ subscript indicates that these effects are likely to vary over time. ${ }^{8}$ The fatalities equation includes a vector of controls $\mathbf{x}_{\mathbf{1} \text { iy }}^{\prime}$ to capture other characteristics about the vehicle and typical drivers of that vehicle. The price equation includes a different vector $\mathbf{x}_{2 \mathbf{i y t}}^{\prime}$ to capture other vehicle characteristics and observation year trends.

One concern with previous estimates of $\phi_{\text {Driver }}^{\text {Driver }}, \phi_{\text {Psngr }}^{\text {Psngr }}, \alpha_{t}^{\text {Driver }}$, and $\alpha_{t}^{\text {Psngr }}$ is omitted variables bias. Because luxury automobiles were first and low-cost imports were last to adopt air bags, cars with a driver's and a passenger's side air bags probably have other features that make them safer and more comfortable than other cars. Additionally, individuals who buy automobiles with air bags may be more careful than average drivers are. To adjust for these potential sources of bias, the current study employs a regression discontinuity strategy based upon model year. For each vehicle model in the data, there are specific model years in which the driver's and the passenger's side air bags were first available. By restricting the data to the model years just before and just after that year for each model it is possible to limit the sample to vehicles that are essentially identical except for the presence of air bags. The direct effects of vintage are controlled for with a quadratic in model year or fixed model year effects, depending on the

\footnotetext{
${ }^{8}$ A more general model would allow the fatality effects to vary by model and consumer and the price effects to vary by model. Expanding the model to allow for these forms of heterogeneity could provide useful insights but is beyond the scope of the current study. When estimated separately by low-, medium-, and high-end vehicle class, the effects of air bags on fatalities and prices are variable across specifications and do not vary systematically with vehicle class (results not shown).
} 
specification. Additionally, many of the specifications control for model fixed effects. After controlling for these factors, all of the variation in air bag availability is driven by some vehicles having been made just before the switch for that model and others having been made just after the switch.

Including Airbag $g_{i y}^{\text {Psngr }}$ in the driver's side and Airbag $_{i y}^{\text {Driver }}$ in the passenger's side fatalities regressions allows for an over-identifying test of the validity of the regression discontinuity strategy. The true values of $\phi_{D r i v e r}^{P s n g r}$ and $\phi_{P S n g r}^{\text {Driver }}$ are assumed to be zero, so that an air bag does not affect fatalities in the adjacent seat. Estimating these parameters in the regressions makes it possible to determine whether the estimated coefficients on these two air bag variables equal to the known values of zero. ${ }^{9}$

\section{B. Willingness to pay and the VSL}

Suppose that, in the early 1990s when air bags were rare, the models that first adopted air bags were those models for which consumer demand for air bags was highest. As in Equation (2), we suppose that the premiums $\alpha_{t}^{\text {Driver }}$ and $\alpha_{t}^{\text {Psngr }}$ on air bags in year $t$ were constant across vehicles. Additionally, suppose that the market for used vehicles was sufficiently "thick" that the marginal buyer's optimal vehicle design could be obtained with or without an air bag. The supply of used cars may be competitive or non-competitive.

If a car buyer purchases a vehicle without an air bag in year $t$, it follows that the buyer values an air bag at less than $\alpha_{t}^{\text {Driver }}$ or $\alpha_{t}^{\text {Psngr }}$. Panel A of Figure 2 shows hypothetical supply and demand curves for air bags in used automobiles in the U.S. The variable plotted along the

\footnotetext{
${ }^{9}$ Another requirement of the discontinuity strategy is that having an air bag does not affect the degree to which one drives safely. A preliminary analysis of the fatality data indicates that, when controls are included, having an air bag has no systematic effect on being the cause of deaths in other vehicles (results not shown).
} 
vertical axis is $\alpha_{t}^{p}$, the premium on having an air bag in position $p$ in year $t$. The variable plotted along the horizontal axis is $Q_{t}^{p}$, the fraction of vehicles sold in year $t$ with air bags in position $p$. As in a typical discrete choice setting, this demand curve represents the surplus obtained from an air bag for each buyer, plotted in decreasing order of willingness to pay. The upward sloping lines represent the supply curves for air bags in 1990 and in 2000. While the stock of automobiles with air bags increased sharply over the decade, preferences for safety over this time were probably relatively constant. ${ }^{10}$ Supposing that the demand curve did not change over this period, the premium on an air bag in 1990 reflected the MWTP for an automobile buyer near the top of the MWTP distribution, and the premium on an air bag in 2000 reflected the MWTP for a buyer closer to the bottom of the distribution. ${ }^{11}$

An air bag is predicted to increase the value of a vehicle by reducing the likelihood of death over the remaining life of the vehicle. Let $\tilde{\phi}_{\text {piyt }}^{p}$ denote the effect of having an air bag in position $p$ on the probability of death for the remaining years that the vehicle is used. While the regression coefficients $\phi_{p}^{\text {Driver }}$ and $\phi_{p}^{\text {Psngr }}$ measure reductions in deaths per year of usage, the parameters $\tilde{\phi}_{\text {piyt }}^{\text {Driver }}$ and $\tilde{\phi}_{\text {piyt }}^{\text {Psngr }}$ measure the reductions in deaths over the multiple years of remaining vehicle life. These parameters are specific to the model (which influences life expectancy), model year, and the year in which the vehicle is being observed. For model $i$ from model year $y$ in observation year $t$, the cost per life saved by purchasing an air bag in position $p$

\footnotetext{
${ }^{10}$ Over the 1980s and 1990s, support for air bag regulation increased somewhat, from 60\% in 1984 to 66\% in 1997 (Nelson, Sussman, and Graham, 1999; New York Times, 1984). However, in 1997, most consumers reported that their beliefs about the effectiveness of air bags had not changed in the past three years. Air bags received considerable attention in the press over the 1990s, and by the mid- to late 1990s - when many of the data for the current study begin -most consumers were already familiar with the positive and negative effects of air bags. Hence, for the period from the late 1990s onward, it is reasonable to suspect that beliefs about air bag effectiveness were roughly constant.

${ }^{11}$ If some buyers postponed their purchases by a year or two until air bags became affordable, then particularly price-sensitive consumers will be underrepresented in the early years and over-represented in the later years. Supposing that such individuals had low valuations of air bags, this shift in behavior in response to the regulation would make the estimated demand curve artificially steep.
} 
can be expressed as $-\alpha_{t}^{p} / \tilde{\phi}_{\text {piyt }}^{p}$. Let $V S L_{i}$ denote the VSL for consumer $i$, let $f($.$) denote its$ population density function (pdf), and let $F($.$) denote the Cumulative Distribution Function$ (CDF) of $V S L_{i}$. Both distributions are unknown, and the aim of this study is to estimate the shape of the CDF $F($.$) . In year t$, the fraction selecting vehicles with air bags in side $p$ can be expressed as $1-F\left(-\alpha_{t}^{p} / \tilde{\phi}_{\text {piyt }}^{p}\right)$. Hence, $-\alpha_{t}^{p} / \tilde{\phi}_{\text {piyt }}^{p}$ can be interpreted as the VSL for the buyer at the $\left(1-Q_{t}^{p}\right)$ th point in the MWTP distribution. ${ }^{12}$ By estimating $\alpha_{t}^{p}, \tilde{\phi}_{\text {piyt }}^{p}$, and $Q_{t}^{p}$ combinations in different years, it is possible to trace out the shape of demand curve for fatality reductions, as illustrated in panel B of Figure 2. The CDF $F($.$) is the same curve plotted with$ $\left(1-Q_{t}^{p}\right)$ rather than $Q_{t}^{p}$ along the horizontal axis. The strategy described here traces out $F($. regardless of whether the increase in supply is caused by regulations or by shifts in production costs.

Importantly, $\tilde{\phi}_{\text {piyt }}^{p}$ is not allowed to vary across consumers. Some of the specifications considered in this paper allow the fatality effect to vary by age, race, and state of residence. The data are not available, however, to measure the degree to which perceived risk varies with driver characteristics such as height, driving ability, and miles driven per year. For this reason, the CDF estimated through this procedure has greater variance than the true CDF of VSLs does, and the variance reflects the variability across buyers in both the VSL and in the perceived efficacy of air bags.

\footnotetext{
${ }^{12}$ For a buyer planning to resell the vehicle, this ratio represents a weighted average of the buyer's VSL over the years driven and the expected future premium on risk reductions through air bags. If the buyer correctly predicts that the air bag will decline in price, then the possibility of resale will lead this estimation procedure to overstate the VSL.
} 


\section{Data and descriptive results}

\section{A. Data description}

The data used in this study come from multiple public and industry sources. Vehicle prices are measured from the Kelley Blue Book and the National Automobile Dealers Association (NADA) used automobile guides. Both datasets include baseline prices as well as some vehicle characteristics and the costs of optional items. Limited versions of both datasets were purchased from the data providers for use in this study. The Kelley Blue Book data include May-June prices by make, model, and model year for three separate regions of the U.S. for the 1997 to 2007 observation years. The NADA data include U.S. average July and January prices by make, model, and model year for observation years from July 1993 through January 2009; January and July prices are averaged together for each observation year after 1993. The Kelley Blue Book estimates are compiled based upon the previous week of sales data, and the NADA estimates are forecasts from four months earlier; both take economic conditions and projections into account when making their estimates.

The total numbers of registered vehicles in the U.S. are measured from two sources. The first, the National Vehicle Population Profile (NVPP), is an industry dataset that was purchased from R.L. Polk, Inc. This dataset is a compilation of the records of the 51 state departments of motor vehicles; state-specific counts by make, model, and model year were purchased biennially for the 1991 to 2005 observation years. To avoid losing observations from the other data sources when NVPP weights are used, vehicle counts for even observation years from 1992 to 2004 were imputed using linear interpolation. The second source of quantity data is the 1984-2005 Consumer Expenditure Survey (CEX). Over this period, the CEX data included the make, model, and model year of all owned vehicles for each family; for the 1996-2005 data, the CEX included 
the same information for leased vehicles. In addition to vehicle counts, the CEX data include demographic characteristics of the owners and leasers and self-reports of automobile characteristics. For owned vehicles, the CEX also includes the year that the vehicle was purchased; this variable is used to estimate the number of buyers of each model and model year of automobile in each year.

Data on automobile fatalities were obtained from the 1974-2006 Fatality Analysis Reporting System (FARS). These data include all automobile fatalities in the U.S., and they measure the make, model, model year, date of event, demographic characteristics of the victim, and the position in the car. In order to compute annual rates of deaths per vehicle, the total fatalities for each model and model year in each observation year are divided by the numbers of registered vehicles of that model, model year, in that observation year, from the NVPP. Additional data on new vehicles’ characteristics for the 1990 to 2003 model years come from the New Car Assessment Program (NCAP) dataset from the National Highway Traffic Safety Administration (NHTSA). The air bags and automatic seat belt variables used in the analysis are constructed from the FARS and NCAP data, as discussed in the appendix.

To combine the six datasets, the make and model names were re-written to conform to common spellings, and some similar vehicles were combined because they were grouped together or indistinguishable in one of the datasets. The final dataset includes 538 make and model combinations, and the average model appears at least once in 5.3 of the six data sources. The CEX, FARS, and NCAP datasets are public, and the datasets and programs will be provided upon request. The Kelley Blue Book, NADA, and NVPP datasets are proprietary, and access to them can be purchased from the data providers. 
Table 1 shows the descriptive statistics for 15 different automobile features other than air bags. Panel A shows the fraction of cars with automatic seatbelts from the FARS data, panel B shows vehicle characteristics from the NCAP, panel C shows characteristics from the NVPP, and panel D shows characteristics reported in the CEX. The first two columns show means and standard deviations from the full samples, and the next two columns show means and standard deviations for the "discontinuity samples.” For each model, the discontinuity samples are restricted to the range of model years from two years before the introduction of driver's side air bags to two years after the introduction of passenger's side air bags. The level of observation is the model $x$ model year combination. The FARS, NCAP, and NVPP data are weighted by the NVPP vehicle quantities and the CEX data are weighted by the CEX vehicle quantities (owned and leased together), both summed over all observation years. The means for the full samples are similar to those in the discontinuity samples, with a few exceptions. For the NCAP data, the discontinuity sample includes cars from an older vintage than those in the full sample, and the vehicles in the discontinuity sample are less likely to have antilock brakes or antitheft devices. In the CEX data, the discontinuity sample includes cars from a slightly more recent vintage than those in the full sample, and the vehicles in the discontinuity sample are slightly more likely to have automotive transmissions, power steering and brakes, and air conditioning.

\section{B. Relationships between air bags and control variables}

In order for regressions of Equations (1) and (2) to produce unbiased estimates, we require that air bag availability is uncorrelated with characteristics about vehicles not included in the regressions. Such a correlation could arise in the discontinuity sample or fixed effects specifications if incorporating air bags into different models coincided with large-scale redesigns 
that added other features as well. In order to evaluate this premise, Table 2 presents linear regressions of the automobile characteristics shown in Table 1, each regressed on the Airbag $g_{i y}^{\text {Driver }}$ and Airbag $_{i y}^{\text {Psngr }}$ dummies. The full samples are used in panels A and B, and the discontinuity samples are used in panels C and D. Each of the regressions in panels A and C includes the air bag dummies and a constant term. Panel B adds model and model year fixed effects. Panel D includes model fixed effects and a linear trend in model year. All of the vehicle characteristics from Table 1 are included except for "SUV or light truck," which is constant within models. The standard errors are adjusted for clustering by model.

The results from Table 1 indicate that air bags are generally correlated with other design features; however, controlling for fixed effects corrects for much of this problem, and including fixed effects in the discontinuity sample appears to address the problem completely. Automatic seatbelts, shown in column (1) are known to be negatively correlated with driver's side air bags due to the regulation. Using the discontinuity sample with fixed effects, a driver's side air bag is associated with -0.572 lower likelihood of having an automatic seatbelt. Among the other 13 automobile characteristics in the full sample without controlling for fixed effects in panel A, we obtain significant coefficients on Airbag $_{i y}^{\text {Driver }}$ and Airbag $g_{i y}^{\text {Psngr }}$ in 7 and 9 and marginally significant coefficients in 2 and 1 of the 13 specifications in panel A. Hence, in a simple regression that uses the full sample and does not include fixed effects, air bags are correlated with many other factors, and the estimated effects of air bags on prices and fatality rates are probably biased. The correlations are moderately-sized and indicate, for example, that having a driver's side air bag is associated with a 22.3 percentage point higher likelihood of having antilock brakes, 94.4 more pounds of weight, and a 9.8 percentage point higher likelihood of having air conditioning. When fixed model and model year effects are included in panel B, most 
of these correlations become smaller and insignificant- we obtain two significant and zero marginally significant coefficients on Airbag $_{\text {iy }}^{\text {Diver }}$ and two significant and two marginally significant coefficients on irbag $_{i y}^{\text {Psngr }}$. When the discontinuity sample is used without fixed effects in panel C, air bags appear to be somewhat correlated with other vehicle features, and the coefficients on Airbag ${ }_{i y}^{\text {Driver }}$ and Airbag ${ }_{i y}^{\text {Psngr }}$ are significant in 3 and 6 and marginally significant in zero and one specifications. When the discontinuity sample is used with model fixed effects and a trend in model year in panel D, these correlations disappear again, and the coefficients on Airbag $g_{i y}^{\text {Driver }}$ and Airbag $_{i y}^{\text {Psngr }}$ are significant in two and zero and marginally significant in one and zero of the 13 specifications.

The correlation between driver's side air bags and antilock brakes is problematic, because it may indicate that other safety features changed at the same time as air bags. To the extent that this correlation is particularly important, readers can focus on the estimates from panel C in which the effect is smaller and insignificant. The correlations between driver's side air bags and automatic seatbelts and antilock brakes are addressed in many of the main specifications by including those variables as controls. Additionally, to test the importance of omitted safety features on our estimates, the fatalities regressions measure the effects of driver's side air bags on passenger's side fatalities and passenger's side air bags on driver's side fatalities. In the specifications with the full set of controls, driver's side air bags are only found to affect driver's side fatalities, and passenger's side air bags are only found to affect passenger's side fatalities.

In addition to biases from omitted vehicle features, regression estimates of the effects of air bags and fatalities could be biased if vehicles with air bags are purchased by particularly safe or careful drivers. To test this hypothesis, Table 3 examines the relationships between air bags and 10 owner/leaser characteristics from the CEX. The setup of the table is the same as in Table 
2. The results are similar to Table 2, with many moderate-sized correlations appearing when the full sample is used with no controls in panel A, but with the correlations generally disappearing when fixed effects are included and the discontinuity sample is used. As panel A shows, families whose vehicles have air bags are slightly older, they have 0.4 to 0.5 years more schooling, higher income, slightly fewer automobiles, and are observed later than families whose vehicles do not

have air bags. Across panel A, the coefficients on Airbag $g_{i y}^{\text {Priver }}$ and Airbag $g_{i y}^{\text {Psngr }}$ are significant in seven and four and marginally significant in zero and two of the ten specifications. When fixed model and model year effects are included in panel B, many of these correlations shrink and become insignificant, and the coefficients on Airbag $_{i y}^{\text {Driver }}$ and Airbag ${ }_{i y}^{\text {Psngr }}$ are significant in three and one and marginally significant in one and two of the ten specifications. When the discontinuity sample is used with no controls in panel C, the correlations between air bags and driver characteristics are smaller than in panel A, but we obtain significant coefficients on Airbag $_{i y}^{\text {Driver }}$ and Airbag $g_{i y}^{\text {Psngr }}$ in six and five of the ten cases. In panel D, relatively few of the owner/leaser characteristics are correlated with air bags, the coefficients on Airbag $g_{i y}^{\text {Driver }}$ and Airbag $_{i y}^{\text {Psngr }}$ are significant in two and zero and marginally significant in one and zero of the ten cases, and most of the correlations are small.

\section{Descriptive results}

Figure 3 presents graphical evidence on the effects of air bags on fatalities, automobile prices, and the numbers of registered vehicles. Each panel presents the sample means for one of the outcome variables, shown separately by the number of model years before or after air bags were introduced into that model, plotted along the horizontal axis. Panels A and B show data on fatalities; panels C and D show prices in 2010 dollars, and panels E and F show quantity. Panels 
$\mathrm{A}, \mathrm{C}$, and $\mathrm{E}$ plot the means of these variables against the number of model years before or after driver's side air bags were added to the model; panels B, D, and F show the corresponding graphs for passenger’s side air bags.

The solid and dashed lines in panels A and B show the rates of drivers' and passengers' fatalities, averaged over the observation years that the model and model year combination appears in the data. These average fatality rates are weighted by the NVPP counts of the numbers of registered vehicles of each type. The results from panels A and B indicate that the introductions of driver's and passenger's side air bags are both associated with drops in both driver's and passenger's side fatalities. For model years prior to the introduction of driver's side air bags, the annual rates of driver's and passenger's side deaths in panel A were roughly 127 and 36 per million. Following the introduction of driver's side air bags, we observe a sharp drop in driver's side fatalities and a reasonable large drop in passenger's side fatalities. For the model years after driver's side air bags were introduced, average driver's and passenger's side fatalities were 106 and 31 per million. In panel B, we observe sharp drops in both driver's and passenger's side fatalities after passenger's side air bags were introduced, with driver's side fatalities declining from 123 to 103 per million and passenger's side fatalities declining from 36 to 30 per million with the introduction of passenger's side air bags. The simultaneity of the drops in drivers' and passengers' side deaths is probability attributable to drivers' and passengers' side air bags being introduced to many models in the same year. We address this simultaneity in the main specifications by using multivariate regressions to estimate separate effects of driver's and passenger's side air bags.

Next, panels $C$ and $D$ show the effects of the driver's and passenger's side air bags on vehicle prices. The solid line shows NADA prices averaged over the 1993 to 2005 observation 
years, and the dashed line shows Kelley Blue Book prices averaged over the 1997 to 2005 observation years. Each price for Kelley Blue Book represents an unweighted mean across the three regional prices. As with panels A and B, the prices are weighted by the number of buyers of each make and model, measured over all of the available years in the CEX. In both panels, the NADA and Kelley Blue Book data produce similar average prices, and in both panels, both data series show steady increases in prices with successive model years, as the later model years correspond to newer cars. Interestingly, none of the four curves exhibit increases in prices at zero, the model years corresponding to the introductions of driver's side and passenger's side air bags. Hence, while air bags appear to reduce fatalities, we do not observe positive effects of air bags on vehicle prices in the average observation year. Hence, before we examine the variation of effects across observation years, the price data appear to indicate a zero VSL.

In panels $\mathrm{E}$ and $\mathrm{F}$, the solid and dashed lines show average numbers of vehicles per year among registered vehicles in the NVPP and among vehicles purchased that year, as reported in the CEX. ${ }^{13}$ The steady declines reflect the lower numbers of vehicle years observed for the later vintage model years. Aside from slight one-year bumps, neither dataset shows a change in vehicle quantities following the introductions of driver's and passenger's side air bags.

\section{Empirical results}

\section{A. Effects of air bags on fatalities and prices}

In order to better understand the relationships between air bags and fatalities, Table 4 presents regression estimates of Equation (1). Panel A shows estimates in which driver's side fatalities per year is the dependent variable; in panel B, the dependent variable is passenger's

\footnotetext{
${ }^{13}$ The high CEX totals suggest a high rate of turnover; however, these totals are weighted sums across survey years with different weighting schemes and may not accurately estimate the total number of buyers in each year.
} 
side fatalities per year. Within each panel, each column shows results from a different ordinary least squares or fixed effects regression in which the regressors of interest are Airbag $_{\text {iy }}^{\text {Driver }}$ and Airbag $g_{i y}^{\text {Psngr }}$, each divided by one million. As in Tables 2 and 3, the level of observation is the model $\mathrm{x}$ model year combination, and all regressions are weighted by the NVPP vehicle quantities. All of the standard errors are adjusted for clustering by vehicle model. In columns (1) to (5), the full sample is used, in columns (6) to (10), the $+/-2$ discontinuity sample is used. Columns (1) and (6) include only the air bag variables and a constant term; columns (2) and (7) add controls for SUV, model year, model year ${ }^{2}$, and SUV interacted with model year and its square. Columns (3) and (8) replace these controls with model and model year fixed effects. Columns (4) and (9) include the same controls as columns (2) and (7) but add the vehicle feature and demographic controls shown in Tables 1 to 3. Columns (5) and (10) include model and model year fixed effects together with the vehicle feature and demographic controls. The samples are relatively small in the specifications in columns (4), (5), (9), and (10) that include the control variables due to the limited numbers of observations that appear in all of the FARS, NCAP, NVPP, and CEX datasets. Drivers' and passenger's side fatalities for the average vehicle are 109.3 and 31.0, respectively, per million years of vehicle life.

The estimated coefficient on driver's side air bags in panel A of Table 4 is negative and significant in all ten specifications, ranging from - 11.61 to -30.26 , indicating that a driver's side air bag reduces the likelihood of a driver's side death in a given year by eleven to thirty per million. The estimated coefficient on passenger's side air bags in panel B is negative in ten, significant in seven, and marginally significant in the remaining three of the ten specifications and ranges from -2.464 to -5.601. Both the driver's side and passenger's side air bags' effects on “own position” fatalities are fairly stable across specifications, and neither changes in a 
systematic way between the full sample and the discontinuity sample or as controls and fixed effects are added to the regressions.

The estimated cross-position effects of air bags on fatalities suggest that the some of the specifications suffer from omitted variables bias, but that the bias becomes less severe as fixed effects and controls are added to the regressions. The estimated coefficient on passenger's side air bags in the driver's side fatalities regression ranges across specifications from -9.479 to +0.196 , is negative in nine, significant in three, and marginally significant in one of the ten specifications. The estimated coefficient on driver's side air bags in the passenger's side fatalities regression ranges from -5.174 to +0.873 , is negative in nine, significant in three, and marginally significant in two of the ten specifications. For all four cases in which the full set of controls is included (columns 5 and 10, panels A and B), however, these cross position effects are insignificant and are small relative to the own position effects.

Given that air bags are effective at decreasing fatalities, it is desirable to measure how much consumers valued these reductions. Table 5 presents estimates of Equation (2). The level of observation is the model $\mathrm{x}$ model year x observation year combination. Each of the columns shows results from a different regression in which the dependent variable is vehicle price. The effects of air bags on prices are assumed to vary linearly with the observation year, and the regressors of interest are Airbag $_{i y}^{\text {Driver }}$, Airbag $_{i y}^{\text {Driver }} *(t-1991)$, Airbag $_{i y}^{\text {Psngr }}$, and $\operatorname{Airbag}_{i y}^{\text {Psngr }} *(t-1991)$. Hence, the coefficients on Airbag ${ }_{i y}^{\text {Driver }}$ and Airbag ${ }_{i y}^{\text {Psngr }}$ measure the premiums on driver's and passenger's side air bags in the 1991 observation year, and the coefficients on Airbag Driver $_{i y}(t-1991)$ and Airbag $_{i y}^{\text {Psngr }} *(t-1991)$ measure the extent to which those premiums change with each successive year. In columns (1) to (6), the Kelley Blue Book price data are used, and in columns (7) to (12) the NADA price data are used. The full 
samples of data are used in columns (1) to (3) and (7) to (9), and the +/- 2 discontinuity samples are used in columns (4) to (7) and (10) to (12). Columns (1), (4), (7), and (10) include controls for SUV, model year, model year², SUV interacted with model year and its square, observation year, and observation year ${ }^{2}$. Columns (2), (5), (8), and (11) replace observation year and observation year ${ }^{2}$ with fixed effects for each model and observation year combination. Columns (3), (6), (9), and (12) add the vehicle attribute controls. The estimates are weighted by CEX counts of vehicle purchases, and the standard errors are adjusted for clustering by model. The average vehicle prices are $\$ 13,900$ in the Kelley Blue Book data and \$12,600 in the NADA data.

The estimates from Table 5 indicate that, in 1991, the premiums on driver's and passenger's side air bags were both large and positive, and the premium on passenger's side air bags was larger than that on driver's side air bags - possibly because passenger's side air bags were relatively rare. All 12 estimated coefficients on Airbag $g_{i y}^{\text {Priver }}$ are positive and significant, ranging across specifications from $\$ 2,020$ to $\$ 7,840$, and all 12 estimated coefficients on Airbag $_{i y}^{\text {Psngr }}$ are positive and significant, with values ranging from $\$ 4,351$ to $\$ 7,700$. The estimated changes in the premiums over time confirm the hypothesis presented in Figure 2 - that the premiums on air bags were large and positive in the early years of the technology when air bags were rare, and they declined in successive years as air bags became more common. The annual change in the premium on Airbag $g_{i y}^{\text {Driver }}$ is negative and significant in all 12 specifications and ranges across specifications from $-\$ 328.0$ to $-\$ 1,076$. The annual change in the premium on Airbag $g_{i y}^{\text {Psngr }}$ is negative and significant in all 12 specifications and ranges from $\$ 484.8$ to $-\$ 735.8$. The estimated coefficients are generally smaller when the discontinuity sample is used relative to the full sample and generally shrink in magnitude as controls are added to the regressions. 
Next, Figure 4 presents estimates of the effects of air bags on prices using a more flexible functional form than the one used in Table 5. Rather than restrict the effects of air bags to vary linearly with the year of observation, the specifications in Figure 4 estimate separate effects of air bags for each year of observation in the data; these separate coefficients are plotted on the vertical axis against observation year, which appears on the horizontal axis. Panels A and C present estimates of the effects of driver's side air bags, and the estimated effects of passenger's side air bags appear in panels B and $\mathrm{D}$. The specifications in panels A and B use the discontinuity sample and include controls for SUV, model year, model year ${ }^{2}$, SUV interacted with model year and its square, observation year, and observation year ${ }^{2}$, as in columns (4) and (10) of Table 5. The specifications in panels C and D add the full set of controls, as in columns (6) and (12) of Table 5. The solid curves show estimates from the NADA data, and the dashed curves show estimates from the Kelley Blue Book data. All four panels use the discontinuity sample, and the regressions are weighted by the CEX numbers of automobile purchases, as in Table 5. The results from Figure 4 generally confirm the story shown by the regressions, and we observe steady declines in both premiums in both specifications.

\section{B. Estimates of the VSL}

The air bag premiums shown in Figure 4 represent the willingness to pay for an air bag for the marginal buyer of a vehicle with an air bag in each observation year. The quantity data, such as those presented in panel B of Figure 1, show at what percentile of the distribution the marginal buyer falls in each year. Putting these estimates together, it is possible to estimate the distribution across drivers of the MWTP for an automobile air bag. Using estimates from Table 4 
of the effect of air bags on fatalities, this distribution of MWTP values can be converted into estimates of the cumulative distribution function (CDF) across drivers of the VSL.

Table 6 walks through calculations of the VSL at the $25^{\text {th }}, 50^{\text {th }}$, and $75^{\text {th }}$ percentiles of the MWTP distribution for driver’s and passenger's side air bags. Estimates using driver's side air bags appear in panel A (rows 1 to 4), and estimates using passenger's side air bags appear in panel B (rows 5 to 8). Columns (1) to (4) show calculations for the $25^{\text {th }}$ percentile, columns (5) to (8) show calculations for the $50^{\text {th }}$ percentile, and columns (9) to (12) show calculations for the $75^{\text {th }}$ percentile. Columns (1), (2), (5), (6), (9), and (10) show estimates with SUV, model year, model year², SUV interacted with model year and its square, observation year, and observation year $^{2}$, as in panels A and B of Figure 4. Columns (3), (4), (7), (8), (11), and (12) add the full set of controls, as in panels C and D of Figure 4. The odd-numbered columns use the price data from Kelley Blue Book, and the even-numbered columns use price data from NADA. The discontinuity sample is used in all of the specifications shown.

Rows 1 and 5 present estimates of the $25^{\text {th }}, 50^{\text {th }}$, and $75^{\text {th }}$ percentiles of the distribution of MWTP for driver's and passenger's side air bags. These percentiles are estimated by identifying adjacent years $Q_{t}^{p}$ and $Q_{t+1}^{p}$ such that $0.25,0.50$, or 0.75 falls within the interval $\left[1-Q_{t}^{p}, 1-\right.$ $\left.Q_{t+1}^{p}\right]$. For the $50^{\text {th }}$ percentile for driver's side air bags, for example, $t$ and $t+1$ are 1998 and 1999; for the $50^{\text {th }}$ percentile for passenger's side air bags, $t$ and $t+1$ are 2001 and 2002. The premium on air bags at that percentile is then estimated as a weighted average of the coefficient estimates $\hat{\alpha}_{t}^{p}$ and $\hat{\alpha}_{t+1}^{p}$ from Figure 4. For a point along the distribution $c \in\{0.25,0.50,0.75\}$, 
the weight $w_{c}^{p}$ is computed as $\frac{c-\left(1-Q_{t+1}^{p}\right)}{Q_{t+1}^{p}-Q_{t}^{p}}$, so that the weighted sum $w_{c}^{p} * \hat{\alpha}_{t}^{p}+\left(1-w_{c}^{p}\right) \hat{\alpha}_{t+1}^{p}$ is a linear interpolation of the MWTPs just above and just below the $100 * c$ th $^{\text {percentile. }}{ }^{14}$

Rows 2 and 6 present estimates of the reduction in fatality risk per million over the remaining life of the vehicle. The total vehicle life $\lambda$ is computed as two times the age of the average purchased vehicle in the full sample, which is roughly 15 years. The vintage $\bar{y}^{p}$ of the marginal vehicle with in air bag in position $p$ is estimated by determining the first model year in which air bags were introduced in position $p$ in each model and averaging across models. The fatality reduction over the remaining years of vehicle life is computed as $\widehat{\phi}_{p}^{p}$ times the remaining vehicle life, where the remaining vehicle life is estimated as the total vehicle life minus the marginal vehicle’s age, or $\lambda-\left[t+\left(1-w_{c}^{p}\right)-\bar{y}^{p}\right]{ }^{15}$

The VSLs at the $25^{\text {th }}, 50^{\text {th }}$, and $75^{\text {th }}$ percentiles of the MWTP distribution are shown in rows 3 and 6. Each VSL estimate is obtained by dividing the premium on an air bag by the risk reduction over the vehicle's remaining life. Hence for position $p$ and centile $c$, the VSL is estimated as $\frac{w_{c}^{p} * \widehat{\alpha}_{t}^{p}+\left(1-w_{c}^{p}\right) \widehat{\alpha}_{t+1}^{p}}{\widehat{\phi}_{p}^{p} *\left(\lambda-\left[t+\left(1-w_{c}^{p}\right)-\bar{y}^{p}\right]\right)}$. The standard errors and confidence intervals do not account for imprecision in the estimation of $w_{c}^{p}$ or the remaining vehicle life. Below each estimate appears a standard error computed using the delta method (nlcom in Stata). To address the imprecision in the linear approximation of the delta method, the line below the standard error shows the Hinkley 95\% confidence interval for the ratio of two random normal variables, as used in Rohlfs (2011b).

\footnotetext{
${ }^{14}$ For the $75^{\text {th }}$ percentile of the MWTP for driver's side air bags and for the $50^{\text {th }}$ percentile for driver's and the $75^{\text {th }}$ percentile for passenger's sides using the Kelley Blue Book data, prices are not available for the adjacent years $Q_{t}^{p}$ and $Q_{t+1}^{p}$, the two earliest years of data are used instead. Similarly, the two latest years of data are used for the $25^{\text {th }}$ percentile of the MWTP for passenger's side air bags. In all cases, the same formula is used for $w_{c}^{p}$.

${ }^{15}$ If vehicle usage (in terms of miles driven) declines with vehicle age, then this parameter may overstate the future risk reductions for older cars and understate them for younger cars, thus overstating the variance in the distribution of VSLs.
} 
The premiums shown in row 1 and 4 of Table 6 confirm the general findings from Figure 4. We observe wide ranges of VSLs across the distribution, with one positive and three moderate-sized negative values at the $25^{\text {th }}$ percentile, and positive values with varying levels of significance at the median and the $75^{\text {th }}$ percentile. At the $25^{\text {th }}$ percentile, the premiums on driver's and passenger's side air bags both change signs across specifications, with values ranging from $-\$ 1,146$ to $+\$ 385.6$ for driver’s side air bags and varying widely from $-\$ 1,711$ to $\$ 2,374$ for passenger’s side air bags. Some buyers may have been legitimately (or possibly overly) concerned about the fatality-increasing effects of air bags for smaller drivers and passengers. If all consumers believed that air bags reduced fatalities, we would expect positive estimates of the value of an air bag for all points along the distribution. These negative values in the specifications with controls probably arise due to mistrust of the technology and unmeasured heterogeneity in the perceived effectiveness of air bags at reducing risk. At the median, the premiums on air bags are positive in all four and significant in three specifications for both driver's and passenger’s side air bags, with values ranging from $\$ 1,126$ to $\$ 3,952$ for the driver’s side and $\$ 648.8$ to $+\$ 3,959$ for the passenger's side. At the $75^{\text {th }}$ percentile, the premiums on driver's and passenger's side air bags are both positive in all four and significant in three specifications and range from $\$ 1,881$ to $\$ 8,117$ for the driver's side and from $\$ 459.7$ to $\$ 5,817$ for the passenger's side.

As row 3 shows, at the $25^{\text {th }}$ percentile, the VSLs implied by the premiums on driver's side air bags range from $-\$ 9.638$ million to $+\$ 2.897$ million and are insignificant in three and marginally significant in one of the four specifications. At the median, the estimated VSLs range across specifications from $\$ 6.557$ million to $\$ 12.96$ million; of the four estimates, two are significant, and one is marginally significant. At the $75^{\text {th }}$ percentile, we obtain four positive and 
estimates ranging from $\$ 7.871$ million to $\$ 17.29$ million; of these four estimates, two are significant and one is marginally significant.

While consumers appear to place similar values on driver's and passenger’s side air bags, the two technologies have very different levels of effectiveness at reducing fatalities. For instance, as the middle columns of row 2 show, at the time that the median buyer determined the premium on a driver's side air bag, the risk reduction per remaining years of vehicle life was 126.1 to 305.0 per million. As the middle columns of row 5 show, however, when the median buyer determined the premium on a passenger’s side air bag, that technology only reduced the risk of death by 35.77 to 45.52 per million. The relatively high valuations of passenger's side air bags may reflect the use of published estimates of air bags' effectiveness and "gut feeling” thinking that do not take into account the lower usefulness of air bags on the passenger's side, or they may reflect a desire for equity in the protection of family members. Due to this discrepancy in risk reductions from the two technologies, the VSLs implied by the premiums on passenger's side air bags are considerably larger in magnitude than those obtained from the premiums on driver's side air bags.

Strangely, at the $25^{\text {th }}$ percentile, when controls are not included, the two VSLs estimates are extremely large at $\$ 65.60$ million and $\$ 122.6$ million; these large estimates are probably the result of upward-biased estimates of the premium on passenger's side air bags, driven by the same factors that led the falsification test to fail when the controls were excluded from the fatalities regressions. When controls are included, the $25^{\text {th }}$ percentile VSLs implied by the

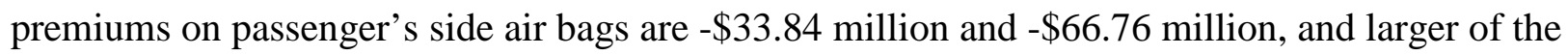
two estimates is significant. At the $50^{\text {th }}$ percentile, the estimated VSLs range from $\$ 15.02$ million to \$114.7 million, with two or three significant coefficients, depending on whether the 
delta method or the Hinkley confidence interval is used. As in row 3, we obtain four positive estimates at the $75^{\text {th }}$ percentile of MWTP for passenger's side air bags in row 6, VSL estimates from $\$ 8.353$ million to $\$ 83.08$ million. As with the median VSL estimates, two or three are significant depending on which measure of precision is used.

Next, panels A and B of Figure 5 show estimated distributions of the VSL for white and Asian buyers and for buyers from other racial categories, and panels $C$ and D show estimated VSL distributions for three separate age groups: 18-29, 30-59, and 60+. Panels A and C use the Kelley Blue Book price data, and panels B and D use the NADA prices. In all four cases, the premiums on air bags are estimated separately by year, as in Figure 4; however, the regressions are weighted by the quantities of vehicles purchased by individuals in that race or age group in the CEX. ${ }^{16}$ For families consisting of individuals from different race or age groups, the weight for vehicle is split equally across the adult family members. Allocating vehicles in this way rather than identifying the primary driver (which is not possible from these data) introduces some measurement error into the race and age variables and may consequently lead to understatement of the VSL differences across demographic groups. Each premium is then divided by $\hat{\phi}_{\text {Driver }}^{\text {Driver }}$ * $\left(\lambda-\left[t-\bar{y}^{p}\right]\right)$, where $\hat{\phi}_{\text {Driver }}^{\text {Driver }}$ is estimated using total fatalities of individuals from that race or age group divided by the group-specific CEX quantity and $\lambda$ and $\bar{y}^{p}$ are estimated using groupspecific weights. The resulting VSL estimates are plotted along the horizontal axis. Plotted along the vertical axis are the fractions of vehicles with owners/leasers whose vehicles had driver's side air bags, estimated separately by year and race or age group. In some cases, the estimated remaining vehicle life was small or negative, leading to highly imprecise (and difficult to

\footnotetext{
${ }^{16}$ While this price is influenced by each of the demographic groups, this price variable accurately describes the premium that each demographic group faced. If $75 \%$ of consumers from that group purchase vehicles with air bags at the market price, then it can be inferred that this market-determined price falls at the $75^{\text {th }}$ percentile of the MWTP distribution for that demographic group.
} 
interpret) estimates of the fatality reduction and consequently of the VSL. For this reason, observation years are not shown if the remaining vehicle life was less than one year. Additionally, the group-specific fatalities regressions are very imprecise when the full set of controls is used. Consequently, the specifications used here are those with only the quadratic in model year interacted with indicator for light truck or SUV, as in panel A of Figure 4.

Previous work from the labor market has found VSLs to be particularly low for historically disadvantaged minorities, due to their relatively low incomes, and among the elderly, due to the lower number of years of life that would be saved by surviving (Aldy and Viscusi, 2007, 2008; Leeth and Ruser, 2003; Smith, Kim, and Taylor, 2004; Viscusi, 2003). While this prediction makes logical sense, there has not previously been plausibly exogenous variation to identify age- or race-specific estimates of the VSL to test this prediction. Interestingly, in the current setting in which there is exogenous variation in risk and the VSL can be consistently identified, neither of these predictions is confirmed. For most points along the distributions shown in panels A and B, the estimated VSL is very similar between whites/Asians and other races. The results from panels $\mathrm{C}$ and $\mathrm{D}$ indicate that, at nearly all points along the distribution, the VSLs for drivers aged 60+ are similar to or slightly greater than the VSLs for drivers aged 30-59.

Another common prediction in the theoretical literature is that the willingness to pay for risk reductions increases with income. While the fatality data do not contain information on driver's incomes, it is possible to estimate the median VSL separately for different states. These state-specific median VSLs are plotted along the vertical axes in the scatterplots in panels A and B of Figure 6. The region-specific Kelley Blue Book price data are used in panel A, and the nationwide NADA prices are used in panel B. Separate price regressions are run for each state 
using the CEX weights of the numbers of vehicles purchased by residents of that state. The fatality effects are estimated separately by the broad Census region in which the vehicle is registered, the state-specific NVPP quantity data are used, and the median VSL is estimated using the same procedure as in Table 6 . In both panels, the specification without fixed effects and extra controls is used. Due to small sample sizes and confidentiality restrictions, many states were not identified in the CEX data, and some respondents' states were changed to preserve confidentiality. Additionally, as in Figure 5, some states were dropped because the remaining vehicle life at the median was less than one year. The final sample includes 25 states in panel A and 36 in panel B. For each state, 2000 median household income is plotted along the horizontal axis. The estimated median VSL ranges widely across states from $-\$ 46.2$ million to $+\$ 65.8$ million using the Kelley Blue Book data in panel A and from $-\$ 75.7$ million to $+\$ 79.0$ million using the NADA prices in panel $\mathrm{B}$; much of this variation is probably due to imprecision in the estimates. The results from Figure 6 provide suggestive evidence of a positive relationship between the VSL and income. Using the Kelley Blue Book data and the NADA data, OLS regressions of median VSL on state income produce statistically insignificant slopes of 0.598 and 0.885 million per $\$ 10,000$ of income.

In order to probe the robustness of the main estimates of this study, Table 7 presents the estimated median VSL values from Table 6 using a handful of modifications of the main specification. The data and sets of controls in columns (1) to (4) and columns (5) to (8) correspond to those used in columns (5) to (8) of Table 6. The first four columns show estimates based upon driver's side air bags, as in panel A of Table 6, and the last four columns show estimates based upon passenger's side air bags, as in panel B of Table 6. Row 1 shows the benchmark estimates that appear in rows 1 and 4 of Table 6 . In row 2, air bags are assumed to 
reduce fatalities by $13 \%$, as cited in Meier (1992); this estimate is representative of the estimates presented in the popular press. When evaluated at the mean fatality level for the driver's side, this estimate predicts a 1,038 to 1,186 reduction in deaths over the life of the vehicle. In row 3 , the marginal effect of air bags on prices is estimated using a regression in which the natural log of price is the dependent variable. In row 4, the linear model for price is used and the marginal effect of air bags on fatalities is estimated using a regression in which the natural log of the fatality rate is the dependent variable. Row 5 uses a strategy similar to that described in Rohlfs (2011b) and estimates the MWTP for an air bag as the price of an air bag minus the slope of the demand curve times the effect of an air bag on quantity demanded; this approach is detailed in the appendix. Finally, row 6 excludes SUVs and light trucks from the sample. In general, the results from the alternative specifications are qualitatively similar to those from the benchmark model; however, there are some notable differences. The log specifications for fatalities (both the 13\% effect in row 2 and the log regression in row 4) lead to considerably larger mean fatalities effects and consequently lower estimated VSLs. The log specification for the price generates somewhat smaller VSL estimates, and both that specification and the specification that excludes SUVs produce some negative estimates.

\section{Conclusion}

Estimates of the VSL are widely regarded as important inputs into policymaking and economic theory. However, researchers have raised many problems with existing estimates and the assumptions that they require for identification. The current study exploits a unique strategy based upon regulation-induced variation in air bag availability in the used car market to obtain new VSL estimates that are less susceptible to these problems. Extensive industry data on 
automobile prices and quantities are used, and they are combined with public data on fatalities and vehicle and consumer attributes. The effects of driver's and passenger's side air bags on fatalities and prices are estimated by exploiting the discontinuous relationship between air bag availability and model year. After controlling for vehicle fixed effects and restricting the sample to model years shortly before and after the introduction of air bags, air bag availability is found to be uncorrelated with other vehicle attributes and consumer characteristics. Driver's side air bags are found to reduce the probability of death in the driver's position by roughly 20 per million per year, and passenger's side air bags are found to reduce the probability of death in the passenger's side position by roughly 4 per million per year. In 1991, when air bags were relatively rare, the point estimates indicate that having a driver's side air bag raised a vehicle's price by $\$ 2,020$ to $\$ 7,840$ and having a passenger's side air bag increased a vehicle’s price by $\$ 4,315$ to $\$ 7,700$ in 2010 dollars. Over time, as air bags became more common, the prices dropped by $\$ 328$ to $\$ 1,076$ per year, and in some specifications, We find that the premiums on air bags were negative in the early 2000s. These negative estimates are probably attributable to beliefs by a substantial fraction of consumers that air bags increase fatalities.

The premiums on driver’s side air bags lead to point estimates of implied VSLs of $-\$ 9.64$ million to $+\$ 2.90$ million at the $25^{\text {th }}$ percentile of the VSL distribution, $\$ 6.56$ million to $\$ 13.0$ million at the median, and $\$ 7.9$ million to $\$ 17.3$ million at the $75^{\text {th }}$ percentile of the VSL distribution. The estimates based upon passenger's side air bags are larger in magnitude, and consumers appear to have valued driver's and passenger's side air bags similarly, despite driver's side air bags' greater effectiveness at reducing fatality risk. The VSL values are found to be similar for white/Asian consumers and for other races and are found to be similar or slightly higher for consumers over age 60 as compared to consumers aged 30-59. Additionally, we 
construct separate VSL estimates by state and find suggestive evidence that the VSL increases at a rate of 0.60 to 0.89 million per $\$ 10,000$ in median household income.

\section{References}

Akre, Jane, 2008. “The value of life lowered,” National Newsdesk, Injury Board. July 16. Available at: http://news.injuryboard.com/the-value-of-life-lowered

Aldy, Joseph E. and W. Kip Viscusi, 2008. "Adjusting the value of a statistical life for age and cohort effects,” Review of Economics and Statistics, 90(3), pp. 573-81.

Aldy, Joseph E. and W. Kip Viscusi, 2007. “Age differences in the value of statistical life: revealed preference evidence," Review of Environmental Economics and Policy, 1(2), pp. 241260.

Ashenfelter, Orley, 2006. "Measuring the value of a statistical life: problems and prospects," Economic Journal 116(510): C10-C23.

Ashenfelter, Orley, and Michael Greenstone, 2004a. "Estimating the value of a statistical life: the importance of omitted variables and publication bias," American Economic Review, 94(2), pp. 454-60.

Ashenfelter, Orley, and Michael Greenstone, 2004b. "Using mandated speed limits to measure the value of a statistical life,” Journal of Political Economy.112(1, pt. 2), pp. S226-67.

Atkinson Scott E. and Robert Halvorsen, 1990. "Evaluation of risks to life: evidence from the market for automobiles,” Review of Economics and Statistics, 72(1), pp. 133-6.

Bartik, Timothy J., 1987. "The estimation of demand parameters in hedonic price models.” Journal of Political Economy, 95(1), pp. 81-8.

Bellis, Mary, 2005. “The history of airbags: the inventors that pioneered airbags.” Available at: http://inventors.about.com/od/astartinventions/a/air_bags.htm. Accessed on July 22, 2011.

Black, Dan A. and Thomas J. Kniesner, 2003. "On the measurement of job risk in hedonic wage models.” Journal of Risk and Uncertainty, 27(3): 205-220.

Borenstein, Seth, 2008. “AP Impact: An American life worth less today,” USA Today, July 11. Available at: http://www.usatoday.com/news/nation/2008-07-10-796349025_x.htm

Corso, Phaedra S., James K. Hammitt, and John D. Graham, 2001. "Valuing mortality-risk reduction: using visual aids to improve the validity of contingent valuation.” Journal of Risk and Uncertainty, 23(2), pp. 165-84. 
Costa, Dora and Matthew Kahn, 2004. “Changes in the Value of Life: 1940-1980.” Journal of Risk and Uncertainty, 29(2), pp.159-80.

de Blaeij, Arianne; Raymond J. G. M. Florax; Piet Rietveld; Erik Verhoef, 2003. "The value of a statistical life in road safety: a meta-analysis.” Accident Analysis and Prevention, 35(6), pp. 973-86.

Dionne, Georges and Paul Lanoie, 2004. "Public choice about the value of a statistical life: the case of road safety.” Journal of Transport Economics and Policy, 38(2), pp. 247-74.

Dreyfus, Mark K. and W. Kip Viscusi, 1995. "Rates of time preference and consumer valuations of automobile safety and fuel efficiency," Journal of Law and Economics, 38(1), pp. 79-105.

Griliches, Zvi, 1979. “Sibling models and data in Economics: beginnings of a survey,” Journal of Political Economy, 87(5 part 2), pp. S37-64.

Hinsberg, Pat, 1992. “Ads inflate desire for air bags; poll shows rise in willingness to pay.” AdWeek. January 6.

Hintermann, Beat, Anna Alberini, and Anil Markandya, 2010. "Estimating the value of safety with labor market data: are the results trustworthy?” Applied Economics, 42(9), pp. 1085100.

Holt, Jim, 2004. “The way we live now: the human factor,” New York Times, March 28.

Holusha, Joshua, 1988. “Company news: airbags on the way as Chrysler gives in,” The New York Times, Section A, Page 1, Column 1; Financial Desk. May 26.

Kelley Blue Book, Co., 1997-2005. Kelley Blue Book Used Car Guide: Consumer Edition. Irvine, CA: Kelly Blue Book.

Kennedy, Alan, 1994. "Popularity inflates demand for airbags, motoring," Sydney Morning Herald (Australia), Motoring; pg. 39. July 15.

Kniesner, Thomas J., W. Kip Viscusi, Christopher Woock, and James P. Ziliak, 2012. “The value of a statistical life: evidence from panel data.” Review of Economics and Statistics, 94(1), pp. 74-87.

Kramer, Larry, 1978. “ $58 \%$ favor passive restraints; seatbelts ignored by public; DOT finds public ignores seatbelts.” The Washington Post, Business and Finance; D1. August 31.

Kurylko, Diana T., 1989. “Chrysler praised, Honda rapped on air-bag use.” Automotive News, Pg. 3 November 27. 
Law, Alex, 1992. “Air bags standard on more Fords,” The Toronto Star, Wheels; Pg. F7. September 26.

Leeth, John D. and John Ruser, 2003. “Compensating wage differentials for fatal and nonfatal injury risk by gender and race,” Journal of Risk and Uncertainty, 27(3), pp. 257-77.

Levin, Doron P., 1990a. “All U.S. Hondas to get air bags by fall of '93.” The New York Times, Section A; Page 21, Column 1; National Desk. September 25.

Levin, Doron P., 1990b. “Auto makers, under pressure, plan air bags in more models,” The New York Times, Section 1; Page 46, Column 4; Style Desk. June 16.

Lexis Nexis Academic Universe, 2007. Search on November 12.

Meier, Barry, 1992. "Study shows air bags save lives, but says seat belts are needed, too.” New York Times, Section A; Page 10; Column 4; National Desk. June 26.

Mount, Timothy, William Schulze, Weifeng Weng, Ning Zhang, and Laurie Chestnut, 2003. "Economic valuation of mortality risk reduction volume II: the effects of age and family status on the value of statistical life - evidence from the automobile market and a national survey of automobile use.” U.S. Environmental Protection Agency Working Paper.

Mrozek, Janusz R. and Laura O. Taylor, 2002. "What determines the value of life? A metaanalysis.” Journal of Policy Analysis and Management, 21(2), pp. 253-70.

National Automobile Dealers Association, 1993-2009. Used automobile price data.

Nelson, Toben F., Dana Sussman and John D. Graham, 1999. “Airbags: an exploratory survey of public knowledge and attitudes.” Accident Analysis and Prevention, 31(4), pp. 371-9.

New York Times, 1984. "Poll finds increase in public's concern over safety in cars.” Section 1; Part 1; Page 22, Column 3; National Desk. July 8.

O’Donnell, Jayne, 1996. “U.S. unveils plan to make air bags safer,” USA Today, Money; Pg. 3B. November 25.

Orlando Sentinel, 1994. “On-off switch for air bags?” Automotive News, April 21.

Ottaway, David B., 1996. “A safety device with a fatal flaw; designed to cushion body, air bags putting short people at risk,” Washington Post, Page A1, October 27.

Public Opinion Strategies. Various surveys.1996-2001.

R.L. Polk and Company. National Vehicle Population Profile.1990-2007. 
Rohlfs, Chris, 2011b. "The economic cost of conscription and an upper bound on the value of a statistical life: hedonic estimates from two margins of response to the Vietnam draft.”

Unpublished paper.

Rohlfs, Chris, 2011b. "Hedonic estimation under very general conditions using experimental and quasi-experimental designs.” Unpublished paper.

Sallee, James, 2011. “The surprising incidence of tax credits for the Toyota Prius,” American Economic Journal: Economic Policy, 3(2), pp. 189-219.

Sawyers, Arlena, 1990. "Survey reveals confusion about air bags.” Automotive News, Marketing and Media, pg. 11. December 24.

Schnier, Kurt E., William C. Horrace, and Ronald G. Felthoven, 2009. "The value of statistical life: pursuing the deadliest catch.” Unpublished paper.

Smith, V. Kerry, Hyun Kim, and Donald H. Taylor, Jr., 2004. "Do the 'near' elderly value mortality risks differently?” Review of Economics and Statistics, 86(1), pp. 423-9.

Thaler, Richard and Sherwin Rosen. "The value of saving a life: evidence from the labor market.” In N.E. Terleckyj (ed.), Household production and consumption. New York: Columbia University Press, pp. 265-300. 1975.

United States $102{ }^{\text {nd }}$ Congress, 1991. "NHTSA authorizations and general provisions: automatic crash protection and safety belt use.” H.R. 2950, Title II, Part B, Section 2508. of Intermodal Surface Transportation Efficiency Act of 1991 (Passed by Both House and Senate).

United States Census Bureau, 2009. “Median household income by state,” Annual Social and Economic Supplement. Available at: http://www.census.gov/hhes/www/income/data/historical/household/H08_2009.xls.

United States Department of Labor, 1984-2005. Bureau of Labor Statistics. Consumer expenditure survey interview survey data and integrated diary and interview survey data [Computer files].ICPSR version. Washington, DC: U.S. Dept. of Labor, Bureau of Labor Statistics [producer], 1990-2008. Ann Arbor, MI: Inter-university Consortium for Political and Social Research [distributor], 1991-2008.

United States Department of Transportation, 1974-2006. National Center for Statistics and Analysis. Fatality analysis reporting system (FARS).

United States Department of Transportation, 1985, 2005. National Highway Traffic Safety Administration. Federal motor vehicle safety standards 208 (FMVSS 208). 49 Code of Federal Regulations § 571.208.

United States Department of Transportation, 1990-2003. National Center for Statistics and Analysis. New car assessment program (NCAP). 
Viscusi, W. Kip, 1993. "The value of risks to life and health.” Journal of Economic Literature, 31(4), pp. 1912-46.

Viscusi, W. Kip, 1996. "Economic foundations of the current regulatory reform efforts," Journal of Economic Perspectives, 10(3), pp. 119-34.

Viscusi, W. Kip, 2003. "Racial differences in the value of statistical life," Journal of Risk and Uncertainty, 27(3), pp. 239-56.

Viscusi, W. Kip and Joseph E. Aldy, 2007. "Labor market estimates of the senior discount for the value of a statistical life," Journal of Environmental Economics and Management, 53(3), pp. $377-92$.

Viscusi, W. Kip and Joseph E. Aldy, 2003. "The value of a statistical life: a critical review of market estimates throughout the world,” Journal of Risk and Uncertainty, 27(1), pp. 5-76.

Wikipedia, 2011."Seat belt.” Available at: http://en.wikipedia.org/wiki/Seat_belt. Accessed on July 21, 2011. 
Table 1: Automobile Features, Full Sample and Discontinuity Sample

Panel A: Fatality Analytic Reporting System (FARS) Data, 1975-2006

Full Sample

Mean $\begin{gathered}\text { Standard } \\ \text { Deviation }\end{gathered}$
+/- 2 Discontinuity Sample

Mean Standard Deviation

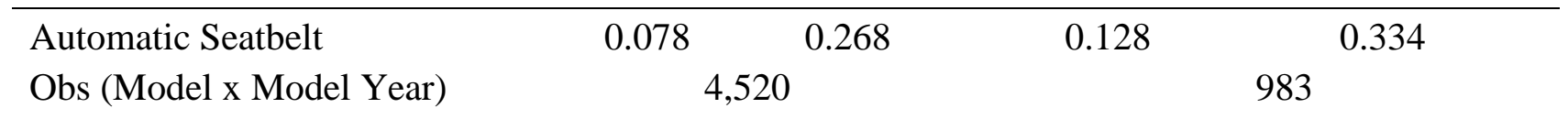

Panel B: New Car Assessment Program (NCAP) Data, 1990-2003

\begin{tabular}{lcccc}
\hline Antilock Brakes & 0.306 & 0.444 & 0.261 & 0.421 \\
Antitheft Device & 0.054 & 0.224 & 0.003 & 0.058 \\
SUV or Light Truck & 0.348 & 0.472 & 0.399 & 0.482 \\
Number of Doors & 3.297 & 0.841 & 3.158 & 0.881 \\
Curb Weight & 3,281 & 628.5 & 3,276 & 601.5 \\
Obs (Model x Model Year) & \multicolumn{2}{c}{1,298} & 427
\end{tabular}

Panel C: National Vehicle Population Profile (NVPP) Data, 1991-2005

\begin{tabular}{lcccc}
\hline Diesel & 0.053 & 0.105 & 0.040 & 0.080 \\
Four Wheel Drive & 0.229 & 0.221 & 0.206 & 0.214 \\
Cylinders & 5.800 & 1.381 & 5.822 & 1.312 \\
Obs (Model x Model Year) & \multicolumn{2}{c}{4,604} & & 1,000
\end{tabular}

Panel D: Consumer Expenditure Survey (CEX), 1984-2005

\begin{tabular}{lcccc}
\hline Automatic Transmission & 0.756 & 0.212 & 0.799 & 0.166 \\
Power Steering & 0.867 & 0.153 & 0.914 & 0.063 \\
Power Brakes & 0.870 & 0.134 & 0.914 & 0.056 \\
Air Conditioning & 0.825 & 0.147 & 0.894 & 0.068 \\
Sun Roof & 0.110 & 0.153 & 0.115 & 0.153 \\
Mileage & 62,015 & 19,874 & 71,325 & 12,684 \\
Obs (Model x Model Year) & \multicolumn{2}{c}{3,826} & 937 \\
\hline \hline
\end{tabular}

Notes to Table 1: The level of observation is the model x model year combination. The +/- 2 discontinuity sample includes model years from two years before the introduction of driver's side air bags to two years after the introduction of passenger's side air bags for each model. The FARS, NCAP, and NVPP data are weighted by the quantity of registered vehicles, summed across the data years, and the CEX data are weighted by the collective weight of consumers with those vehicles (finlwt21 added across families by model x model year combination, summed across data years). The CEX data measure each family's owned vehicles for all years and each family's leased vehicles for 1996-2005 (the only available years for leased vehicles). Antilock brakes and antitheft device in the NCAP measure whether the feature was standard in a model. Additional details in the text. 
Table 2: Relationships Between Air Bag Variables and Other Vehicle Features

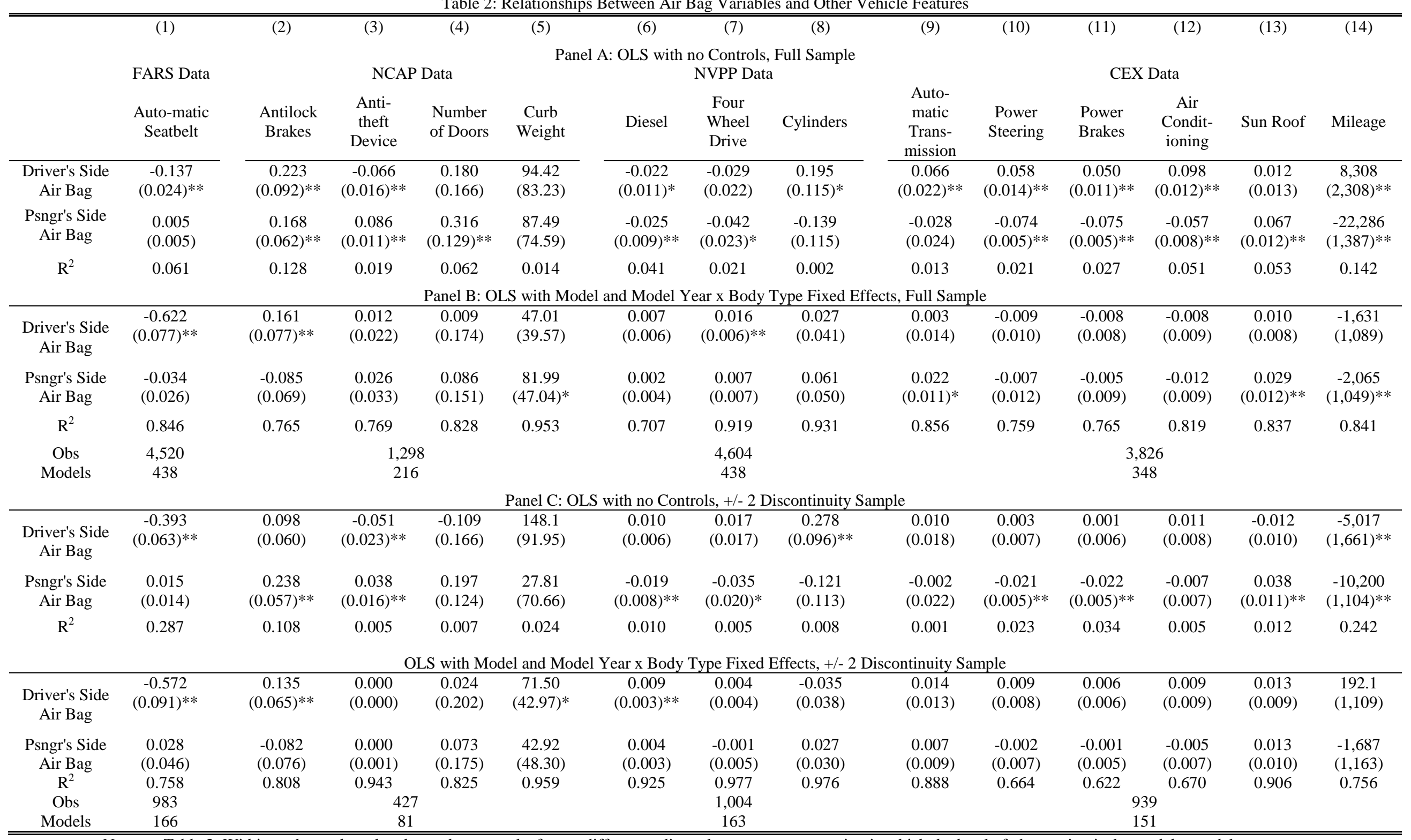

Notes to Table 2: Within each panel, each column shows results from a different ordinary least squares regression in which the level of observation is the model x model year combination and the regressors of interest are dummies for whether that model had driver's side and passenger's side air bags in that model year. The dependent variables are the vehicle features shown in Table 1 . The full samples, discontinuity samples, and sample weights are the same as in Table 1 . Standard errors adjust for clustering by model. 
Table 3: Relationships Between Air Bag Variables and Driver Characteristics, CEX 1984-2005

\begin{tabular}{|c|c|c|c|c|c|c|c|c|c|c|}
\hline & (1) & (2) & (3) & (4) & (5) & (6) & (7) & (8) & (9) & $(10)$ \\
\hline \multicolumn{11}{|c|}{ Panel A: OLS with no Controls, Full Sample } \\
\hline & $\begin{array}{l}\text { Family } \\
\text { Size }\end{array}$ & Age & White/Asian & Female & Married & $\begin{array}{c}\text { Years of } \\
\text { Schooling }\end{array}$ & $\begin{array}{l}\text { Annual } \\
\text { Income }\end{array}$ & $\begin{array}{c}\text { Year of } \\
\text { Observation }\end{array}$ & $\begin{array}{c}\text { Number of } \\
\text { Automobiles }\end{array}$ & $\begin{array}{c}\text { Quarterly Insurance } \\
\text { Cost per Auto }\end{array}$ \\
\hline $\begin{array}{l}\text { Driver's Side } \\
\text { air bag }\end{array}$ & $\begin{array}{c}0.003 \\
(0.054)\end{array}$ & $\begin{array}{c}1.209 \\
(0.524)^{* *}\end{array}$ & $\begin{array}{c}0.001 \\
(0.004)\end{array}$ & $\begin{array}{c}0.007 \\
(0.005)\end{array}$ & $\begin{array}{c}0.021 \\
(0.005)^{* *}\end{array}$ & $\begin{array}{c}0.528 \\
(0.055)^{* *}\end{array}$ & $\begin{array}{c}3,490 \\
(933.1)^{* *}\end{array}$ & $\begin{array}{c}4.874 \\
(0.161)^{* *}\end{array}$ & $\begin{array}{c}-0.226 \\
(0.037)^{* *}\end{array}$ & $\begin{array}{c}25.85 \\
(12.47)^{* *}\end{array}$ \\
\hline $\begin{array}{l}\text { Psngr's Side } \\
\text { air bag }\end{array}$ & $\begin{array}{l}-0.038 \\
(0.056)\end{array}$ & $\begin{array}{c}0.327 \\
(0.578)\end{array}$ & $\begin{array}{c}-0.008 \\
(0.004)^{*}\end{array}$ & $\begin{array}{c}0.009 \\
(0.005)^{*}\end{array}$ & $\begin{array}{c}0.004 \\
(0.007)\end{array}$ & $\begin{array}{c}0.358 \\
(0.060)^{* *}\end{array}$ & $\begin{array}{c}8,044 \\
(1,318)^{* *}\end{array}$ & $\begin{array}{c}2.732 \\
(0.109)^{* *}\end{array}$ & $\begin{array}{l}-0.053 \\
(0.037)\end{array}$ & $\begin{array}{c}66.82 \\
(15.40)^{* *}\end{array}$ \\
\hline $\mathrm{R}^{2}$ & 0.002 & 0.014 & 0.004 & 0.019 & 0.025 & 0.241 & 0.105 & 0.666 & 0.110 & 0.019 \\
\hline \multicolumn{11}{|c|}{ Panel B: OLS with Model and Model Year x Body Type Fixed Effects, Full Sample } \\
\hline $\begin{array}{l}\text { Driver's Side } \\
\text { air bag }\end{array}$ & $\begin{array}{l}-0.034 \\
(0.026)\end{array}$ & $\begin{array}{c}0.096 \\
(0.336)\end{array}$ & $\begin{array}{c}0.009 \\
(0.005)^{* *}\end{array}$ & $\begin{array}{c}0.008 \\
(0.004)^{* *}\end{array}$ & $\begin{array}{c}0.008 \\
(0.006)\end{array}$ & $\begin{array}{c}0.147 \\
(0.038)^{* *}\end{array}$ & $\begin{array}{c}1,568 \\
(830.0)^{*}\end{array}$ & $\begin{array}{l}-0.046 \\
(0.072)\end{array}$ & $\begin{array}{c}0.001 \\
(0.013)\end{array}$ & $\begin{array}{c}26.74 \\
(17.07)\end{array}$ \\
\hline $\begin{array}{l}\text { Psngr's Side } \\
\text { air bag }\end{array}$ & $\begin{array}{c}0.035 \\
(0.036)\end{array}$ & $\begin{array}{c}-0.807 \\
(0.466)^{*}\end{array}$ & $\begin{array}{l}-0.001 \\
(0.006)\end{array}$ & $\begin{array}{l}-0.005 \\
(0.004)\end{array}$ & $\begin{array}{c}0.000 \\
(0.007)\end{array}$ & $\begin{array}{c}0.045 \\
(0.050)\end{array}$ & $\begin{array}{c}1,348 \\
(1,051)\end{array}$ & $\begin{array}{c}-0.174 \\
(0.087)^{* *}\end{array}$ & $\begin{array}{l}-0.018 \\
(0.013)\end{array}$ & $\begin{array}{c}40.41 \\
(21.67)^{*}\end{array}$ \\
\hline $\mathrm{R}^{2}$ & 0.683 & 0.815 & 0.433 & 0.583 & 0.546 & 0.837 & 0.643 & 0.981 & 0.891 & 0.174 \\
\hline $\begin{array}{c}\text { Obs } \\
\text { Models }\end{array}$ & & & & & & $\begin{array}{c}3,826 \\
348\end{array}$ & & & & \\
\hline \multicolumn{11}{|c|}{ Panel C: OLS with no Controls, +/- 2 Discontinuity Sample } \\
\hline $\begin{array}{l}\text { Driver's side } \\
\text { air bag }\end{array}$ & $\begin{array}{c}0.018 \\
(0.044)\end{array}$ & $\begin{array}{c}0.331 \\
(0.490)\end{array}$ & $\begin{array}{c}0.009 \\
(0.004)^{* *}\end{array}$ & $\begin{array}{c}0.002 \\
(0.005)\end{array}$ & $\begin{array}{c}0.016 \\
(0.005)^{* *}\end{array}$ & $\begin{array}{c}0.197 \\
(0.053)^{* *}\end{array}$ & $\begin{array}{c}1,911 \\
(833.8)^{* *}\end{array}$ & $\begin{array}{c}1.490 \\
(0.162)^{* *}\end{array}$ & $\begin{array}{c}-0.124 \\
(0.036)^{* *}\end{array}$ & $\begin{array}{c}10.11 \\
(14.40)\end{array}$ \\
\hline $\begin{array}{l}\text { Psngr's side } \\
\text { air bag }\end{array}$ & $\begin{array}{l}-0.007 \\
(0.041)\end{array}$ & $\begin{array}{c}-0.241 \\
(0.487)\end{array}$ & $\begin{array}{c}-0.011 \\
(0.005)^{* *}\end{array}$ & $\begin{array}{c}0.001 \\
(0.004)\end{array}$ & $\begin{array}{c}0.001 \\
(0.007)\end{array}$ & $\begin{array}{c}0.166 \\
(0.057)^{* *}\end{array}$ & $\begin{array}{c}3,087 \\
(1,278)^{* *}\end{array}$ & $\begin{array}{c}1.504 \\
(0.156)^{* *}\end{array}$ & $\begin{array}{l}-0.025 \\
(0.032)\end{array}$ & $\begin{array}{c}44.91 \\
(18.35)^{* *}\end{array}$ \\
\hline $\mathrm{R}^{2}$ & 0.000 & 0.001 & 0.008 & 0.000 & 0.010 & 0.049 & 0.026 & 0.473 & 0.028 & 0.014 \\
\hline \multicolumn{11}{|c|}{ OLS with Model and Model Year x Body Type Fixed Effects, +/- 2 Discontinuity Sample } \\
\hline $\begin{array}{c}\text { Driver's side } \\
\text { air bag }\end{array}$ & $\begin{array}{c}-0.072 \\
(0.032)^{* *}\end{array}$ & $\begin{array}{l}-0.039 \\
(0.415)\end{array}$ & $\begin{array}{c}0.003 \\
(0.006)\end{array}$ & $\begin{array}{c}0.009 \\
(0.005)^{*}\end{array}$ & $\begin{array}{l}-0.008 \\
(0.007)\end{array}$ & $\begin{array}{c}0.159 \\
(0.041)^{* *}\end{array}$ & $\begin{array}{l}1,249.8 \\
(936.3)\end{array}$ & $\begin{array}{c}0.071 \\
(0.061)\end{array}$ & $\begin{array}{c}0.014 \\
(0.015)\end{array}$ & $\begin{array}{c}3.832 \\
(19.37)\end{array}$ \\
\hline $\begin{array}{l}\text { Psngr's side } \\
\text { air bag }\end{array}$ & $\begin{array}{c}0.004 \\
(0.036)\end{array}$ & $\begin{array}{c}-0.237 \\
(0.394)\end{array}$ & $\begin{array}{c}-0.001 \\
(0.006)\end{array}$ & $\begin{array}{c}-0.006 \\
(0.004)\end{array}$ & $\begin{array}{c}-0.002 \\
(0.009)\end{array}$ & $\begin{array}{c}0.010 \\
(0.058)\end{array}$ & $\begin{array}{c}736.1 \\
(1,216)\end{array}$ & $\begin{array}{c}-0.077 \\
(0.079)\end{array}$ & $\begin{array}{c}-0.020 \\
(0.015)\end{array}$ & $\begin{array}{c}6.953 \\
(25.70)\end{array}$ \\
\hline $\begin{array}{c}\mathrm{R}^{2} \\
\text { Obs } \\
\text { Models }\end{array}$ & 0.797 & 0.902 & 0.551 & 0.633 & 0.619 & $\begin{array}{l}0.800 \\
937 \\
151\end{array}$ & 0.679 & 0.943 & 0.913 & 0.410 \\
\hline
\end{tabular}

Notes to Table 3: Within each panel, each column shows results from an OLS regression. The setup of this table is the same as in Table 2; however, the dependent variables measure the characteristics of the families in the CEX who owned or leased the models in question. The samples, weighting, and clustering are the same as in the CEX data in panel C of Table 1 and in columns (8) to (13) of Table 2. 
Table 4: Effects of Air Bags on Fatalities per Vehicle Year, FARS 1985-2006

\begin{tabular}{|c|c|c|c|c|c|c|c|c|c|c|}
\hline & $(1)$ & $(2)$ & (3) & $(4)$ & (5) & (6) & (7) & (8) & (9) & $(10)$ \\
\hline \multicolumn{11}{|c|}{ Panel A: Driver's Side Fatalities per Vehicle x Year } \\
\hline & \multicolumn{5}{|c|}{ Full Sample } & \multicolumn{5}{|c|}{ +/- 2 Discontinuity Sample } \\
\hline $\begin{array}{l}\text { Driver's side air } \\
\text { bag/1,000,000 }\end{array}$ & $\begin{array}{c}-11.61 \\
(3.359)^{* *}\end{array}$ & $\begin{array}{c}-23.18 \\
(3.168)^{* *}\end{array}$ & $\begin{array}{c}-20.54 \\
(4.281)^{* *}\end{array}$ & $\begin{array}{c}-22.22 \\
(8.239)^{* *}\end{array}$ & $\begin{array}{c}-20.37 \\
(7.543)^{* *}\end{array}$ & $\begin{array}{c}-22.16 \\
(3.433) * *\end{array}$ & $\begin{array}{c}-30.26 \\
(3.806)^{* *}\end{array}$ & $\begin{array}{c}-20.40 \\
(3.731)^{* *}\end{array}$ & $\begin{array}{c}-16.25 \\
(7.928)^{* *}\end{array}$ & $\begin{array}{c}-14.29 \\
(7.516)^{*}\end{array}$ \\
\hline $\begin{array}{l}\text { Psngr's side air } \\
\text { bag/1,000,000 }\end{array}$ & $\begin{array}{c}-9.155 \\
(4.387)^{* *}\end{array}$ & $\begin{array}{c}-7.732 \\
(4.305)^{*}\end{array}$ & $\begin{array}{l}-3.867 \\
(3.048)\end{array}$ & $\begin{array}{c}0.196 \\
(4.196)\end{array}$ & $\begin{array}{l}-0.783 \\
(3.834)\end{array}$ & $\begin{array}{l}-4.089 \\
(4.313)\end{array}$ & $\begin{array}{c}-9.479 \\
(4.714)^{* *}\end{array}$ & $\begin{array}{c}-8.870 \\
(4.179) * *\end{array}$ & $\begin{array}{l}-1.197 \\
(4.196)\end{array}$ & $\begin{array}{l}-6.555 \\
(4.794)\end{array}$ \\
\hline $\mathrm{R}^{2}$ & 0.014 & 0.031 & 0.211 & 0.500 & 0.761 & 0.025 & 0.057 & 0.438 & 0.474 & 0.813 \\
\hline \multicolumn{11}{|c|}{ Panel B: Passenger's Side Fatalities per Vehicle x Year } \\
\hline $\begin{array}{l}\text { Driver's side air } \\
\text { bag/1,000,000 }\end{array}$ & $\begin{array}{c}0.873 \\
(1.366)\end{array}$ & $\begin{array}{c}-2.530 \\
(1.241)^{* *}\end{array}$ & $\begin{array}{c}-2.734 \\
(1.470)^{*}\end{array}$ & $\begin{array}{l}-2.480 \\
(2.780)\end{array}$ & $\begin{array}{l}-2.732 \\
(1.945)\end{array}$ & $\begin{array}{c}-3.847 \\
(1.505)^{* *}\end{array}$ & $\begin{array}{c}-5.174 \\
(1.518)^{* *}\end{array}$ & $\begin{array}{c}-2.680 \\
(1.599)^{*}\end{array}$ & $\begin{array}{l}-1.548 \\
(2.742)\end{array}$ & $\begin{array}{l}-2.840 \\
(2.012)\end{array}$ \\
\hline $\begin{array}{l}\text { Psngr's side air } \\
\text { bag/1,000,000 }\end{array}$ & $\begin{array}{c}-3.567 \\
(1.744)^{* *}\end{array}$ & $\begin{array}{c}-3.668 \\
(1.613)^{* *}\end{array}$ & $\begin{array}{c}-3.917 \\
(1.268)^{* *}\end{array}$ & $\begin{array}{c}-2.464 \\
(1.485)^{*}\end{array}$ & $\begin{array}{c}-4.040 \\
(1.502)^{* *}\end{array}$ & $\begin{array}{c}-2.980 \\
(1.759)^{*}\end{array}$ & $\begin{array}{c}-3.803 \\
(1.588)^{* *}\end{array}$ & $\begin{array}{c}-5.601 \\
(1.431)^{* *}\end{array}$ & $\begin{array}{c}-3.220 \\
(1.720)^{*}\end{array}$ & $\begin{array}{c}-4.591 \\
(1.959)^{* *}\end{array}$ \\
\hline $\mathrm{R}^{2}$ & 0.003 & 0.043 & 0.225 & 0.348 & 0.685 & 0.027 & 0.155 & 0.660 & 0.395 & 0.751 \\
\hline $\begin{array}{l}\text { Controls include ... } \\
\text { Model Year \& } \\
\text { Model Year }{ }^{2} \text { x } \\
\text { Body Type } \\
\text { Model FEs }\end{array}$ & & Yes & Yes & Yes & Yes & & Yes & Yes & Yes & Yes \\
\hline $\begin{array}{l}\text { Model Year x } \\
\text { Body Type FEs }\end{array}$ & & & Yes & & Yes & & & Yes & & Yes \\
\hline $\begin{array}{l}\text { Auto Attributes } \\
\text { Driver Attributes }\end{array}$ & & & & $\begin{array}{l}\text { Yes } \\
\text { Yes }\end{array}$ & $\begin{array}{l}\text { Yes } \\
\text { Yes }\end{array}$ & & & & $\begin{array}{l}\text { Yes } \\
\text { Yes }\end{array}$ & $\begin{array}{l}\text { Yes } \\
\text { Yes }\end{array}$ \\
\hline $\begin{array}{c}\text { Obs } \\
\text { Models }\end{array}$ & & $\begin{array}{c}4,318 \\
433\end{array}$ & & & & & $\begin{array}{c}1,287 \\
303\end{array}$ & & & \\
\hline
\end{tabular}

Notes to Table 4: Within each panel, each column shows results from a single OLS regression in which the dependent variable is annual fatalities per registered vehicles of that model and model year. The data are the same as in Tables 1 to 3 and Figures 1 and 3. Model year and its square, when included, are interacted with an indicator for SUV. The auto attribute controls are the same as in Tables 1 and 2; the driver attribute controls are the same as in Table 3. 
Table 5: Effects of Air Bags on Automobile Prices

\begin{tabular}{|c|c|c|c|c|c|c|c|c|c|c|c|c|}
\hline \multirow{4}{*}{ Driver's Side Airbag } & \multirow[t]{3}{*}{ (1) } & $(2)$ & (3) & (4) & (5) & (6) & (7) & (8) & (9) & (10) & (11) & $(12)$ \\
\hline & & \multicolumn{5}{|c|}{ Panel A: Kelley Blue Book Prices, 1997-2005 } & \multicolumn{6}{|c|}{$\begin{array}{l}\text { Panel B: National Automobile Dealers Association (NADA) Prices, 1993- } \\
\qquad 2005\end{array}$} \\
\hline & & \multicolumn{2}{|c|}{ Full Sample } & \multicolumn{3}{|c|}{ +/- 2 Discontinuity Sample } & \multicolumn{3}{|c|}{ Full Sample } & \multicolumn{3}{|c|}{ +/- 2 Discontinuity Sample } \\
\hline & $\begin{array}{l}\$ 7,695 \\
(650.3)^{* *}\end{array}$ & $\begin{array}{l}\$ 5,508 \\
(645.8)^{* *}\end{array}$ & $\begin{array}{l}\$ 2,741 \\
(813.6)^{* *}\end{array}$ & $\begin{array}{l}\$ 4,181 \\
(811.8)^{* *}\end{array}$ & $\begin{array}{l}\$ 2,808 \\
(508.0)^{* *}\end{array}$ & $\begin{array}{l}\$ 2,020 \\
(688.8)^{* *}\end{array}$ & $\begin{array}{c}\$ 7,840 \\
(944.0)^{* *}\end{array}$ & $\begin{array}{c}\$ 6,830 \\
(452.8)^{* *}\end{array}$ & $\begin{array}{l}\$ 3,587 \\
(460.0)^{* *}\end{array}$ & $\begin{array}{l}\$ 3,936 \\
(926.4)^{* *}\end{array}$ & $\begin{array}{c}\$ 3,833 \\
(524.6)^{* *}\end{array}$ & $\begin{array}{c}\$ 3,092 \\
(544.1)^{* *}\end{array}$ \\
\hline $\begin{array}{l}\text { Driver's Side Airbag } \\
* \text { (Obs Year -1991) }\end{array}$ & $\begin{array}{l}-\$ 824.6 \\
(57.47)^{* *}\end{array}$ & $\begin{array}{c}-\$ 764.7 \\
(58.53)^{* *}\end{array}$ & $\begin{array}{c}-\$ 376.2 \\
(85.45)^{* *}\end{array}$ & $\begin{array}{c}-\$ 452.9 \\
(70.31)^{* *}\end{array}$ & $\begin{array}{c}-\$ 439.3 \\
(60.14)^{* *}\end{array}$ & $\begin{array}{l}-\$ 328.0 \\
(58.60)^{* *}\end{array}$ & $\begin{array}{c}-\$ 1,076 \\
(65.55)^{* *}\end{array}$ & $\begin{array}{c}-\$ 1,041 \\
(53.48)^{* *}\end{array}$ & $\begin{array}{c}-\$ 497.4 \\
(59.02)^{* *}\end{array}$ & $\begin{array}{c}-\$ 540.9 \\
(61.01)^{* *}\end{array}$ & $\begin{array}{c}-\$ 567.9 \\
(60.76)^{* *}\end{array}$ & $\begin{array}{c}-\$ 404.6 \\
(64.66)^{* *}\end{array}$ \\
\hline Psngr's Side Airbag & $\begin{array}{c}\$ 7,131 \\
(1,582)^{* *}\end{array}$ & $\begin{array}{c}\$ 6,348 \\
(1,355)^{* *}\end{array}$ & $\begin{array}{c}\$ 5,507 \\
(1,854)^{* *}\end{array}$ & $\begin{array}{c}\$ 7,668 \\
(1,253)^{* *}\end{array}$ & $\begin{array}{c}\$ 4,839 \\
(1,219)^{* *}\end{array}$ & $\begin{array}{c}\$ 4,315 \\
(1,420)^{* *}\end{array}$ & $\begin{array}{c}\$ 7,624 \\
(1,352)^{* *}\end{array}$ & $\begin{array}{c}\$ 6,911 \\
(760.4)^{* *}\end{array}$ & $\begin{array}{c}\$ 5,906 \\
(783.7)^{* *}\end{array}$ & $\begin{array}{c}\$ 7,700 \\
(1,065)^{* *}\end{array}$ & $\begin{array}{c}\$ 6,157 \\
(643.2)^{* *}\end{array}$ & $\begin{array}{c}\$ 5,344 \\
(715.4)^{* *}\end{array}$ \\
\hline $\begin{array}{l}\text { Psngr's Side Airbag } \\
* \text { (Obs Year -1991) }\end{array}$ & $\begin{array}{c}-\$ 493.0 \\
(153.4)^{* *}\end{array}$ & $\begin{array}{c}-\$ 714.9 \\
(138.5)^{* *}\end{array}$ & $\begin{array}{c}-\$ 702.7 \\
(171.7)^{* *}\end{array}$ & $\begin{array}{c}-\$ 511.3 \\
(128.9)^{* *}\end{array}$ & $\begin{array}{c}-\$ 523.8 \\
(127.5)^{* *}\end{array}$ & $\begin{array}{c}-\$ 484.8 \\
(157.3)^{* *}\end{array}$ & $\begin{array}{c}-\$ 602.9 \\
(113.9)^{* *}\end{array}$ & $\begin{array}{c}-\$ 721.8 \\
(85.35)^{* *}\end{array}$ & $\begin{array}{c}-\$ 735.8 \\
(76.68)^{* *}\end{array}$ & $\begin{array}{c}-\$ 557.9 \\
(77.73)^{* *}\end{array}$ & $\begin{array}{c}-\$ 657.0 \\
(63.75)^{* *}\end{array}$ & $\begin{array}{l}-\$ 622.8 \\
(78.77)\end{array}$ \\
\hline $\mathrm{R}^{2}$ & 0.652 & 0.905 & 0.908 & 0.701 & 0.942 & 0.943 & 0.720 & 0.936 & 0.960 & 0.695 & 0.965 & 0.976 \\
\hline Obs & 13, & 318 & 5,809 & 4,7 & & 2,970 & 18 & 381 & 6,837 & 6,4 & & 4,324 \\
\hline Models & & 93 & 183 & 12 & & 99 & & 13 & 187 & & 4 & 90 \\
\hline \multicolumn{13}{|l|}{ Controls include ... } \\
\hline $\begin{array}{l}\text { Model Year \& } \\
\text { Model Year }{ }^{2}\end{array}$ & Yes & & & Yes & & & Yes & & & Yes & & \\
\hline $\begin{array}{l}\text { Obs Year \& } \\
\text { Obs Year }\end{array}$ & Yes & & & Yes & & & Yes & & & Yes & & \\
\hline $\begin{array}{l}\text { Model x Obs } \\
\text { Year FEs }\end{array}$ & & Yes & Yes & & Yes & Yes & & Yes & Yes & & Yes & Yes \\
\hline $\begin{array}{l}\text { Model Year x } \\
\text { Body Type } \\
\text { FEs }\end{array}$ & & Yes & Yes & & Yes & Yes & & Yes & Yes & & Yes & Yes \\
\hline $\begin{array}{l}\text { Auto } \\
\text { Attributes }\end{array}$ & & & Yes & & & Yes & & & Yes & & & Yes \\
\hline
\end{tabular}

Notes to Table 5: Each column shows results from a different OLS regression. The level of observation is the model $\mathrm{x}$ model year $\mathrm{x}$ observation year

combination. The price data are the same as in Figure 3 and are weighted by total numbers of vehicles of that model and model year purchased that observation year, as measured in the CEX. All prices are measured in constant 2010 dollars. The samples are the same as in Tables 1 to 4 . The auto attributes are the same as in Tables 1 and 2. Standard errors adjust for clustering by model. 
Table 6: Willingness to Pay for an Air Bag, Risk Reduction, and Estimated Value of a Statistical Life at the 25th, 50th, and 75th Percentiles

Panel A: Driver's Side

25th Percentile of the WTP Distribution

$\begin{array}{cc} & \text { Add Controls and } \\ \text { Body Type x Model } & \text { Model and Body } \\ \text { Year \& Model Year } & \text { Type x Model Yea }\end{array}$

50th Percentile of the WTP Distribution

$\begin{array}{cc} & \text { Add Controls and } \\ \text { Body Type x Model } & \text { Model and Body } \\ \text { Year \& Model Year } & \text { Type x Model Year }\end{array}$

Type x Model Year FEs

Kelley

Blue

Book

WTP for an Air

bag in 2010

Dollars

Risk Reduction

2. per Million Over

Remaining

Vehicle Life

3. Implied VSL in

Millions (delta

method s.e.)

Hinkley 95\% CI

$\$ 385.6$

(492.1)

Kelley

Blue NADA

$-\$ 1,146 \quad-\$ 606.0 \quad-\$ 371.4$

$\begin{array}{ccc}-\$ 1,146 & -\$ 606.0 & -\$ 371.4 \\ (642.1)^{*} & (558.8)^{* *} & (289.2)^{* *}\end{array}$

\& Model Year ${ }^{2}$

Type x Model Year FEs

Blue NADA Blue NADA

Book Book

$\$ 3,952 \quad \$ 1,751 \quad \$ 1,555$

$(973.0)^{* *} \quad(729.7)^{* *} \quad(1,274)$

$\$ 1,126$

$\$ 1,126$
$(297.0)^{* *}$

$\begin{array}{cccc}133.1 & 150.4 & 62.87 & 71.04\end{array}$

$\begin{array}{cccc}133.1 & 150.4 & 62.87 & 71.04 \\ (16.74)^{* *} & (18.91)^{* *} & (33.06)^{*} & (37.35)^{*}\end{array}$

$(38.36)^{* *}$

267.0

144.1

126.1

(66.30)*

\$12.96 \$6.557 \$10.79 \$8.926

$\$ 2.897 \quad-\$ 7.617 \quad-\$ 9.638 \quad-\$ 5.228$

$\begin{array}{llll}(3.715) & (4.375)^{*} \quad(10.23) \quad(4.912)\end{array}$

$(3.582)^{* *} \quad(2.855)^{* *}$

$[-4.431, \quad[-16.97, \quad[-77.40, \quad[-39.65$,

10.60] 0.752$\left.\left.]^{*} \quad 25.18\right] \quad 11.28\right]$

$[6.503, \quad[1.193, \quad[-24.59, \quad[-19.89$,

$\begin{array}{llll} & 21.09]^{* *} & 12.77]^{* *} & 83.16\end{array}$

Panel B: Passenger's Side

4. WTP for an air

bag in 2010

Dollars

5. Risk Reduction

per Million Over

Remaining

Vehicle Life

6. Implied VSL in

Millions (delta

method s.e.)

Hinkley 95\% CI

\begin{tabular}{ccccccc}
\hline$\$ 2,374$ & $\$ 1,393$ & $-\$ 791.0$ & $-\$ 1,711$ & $\$ 3,959$ & $\$ 4,326$ & $\$ 648.8$ \\
$(592.6)$ & $(573.9)^{* *}$ & $(631.7)$ & $(357.2)^{* *}$ & $(644.6)^{* *}$ & $(745.4)^{* *}$ & $(684.7)$
\end{tabular}

$\begin{array}{llll}19.36 & 21.23 & 23.37 & 25.63\end{array}$

$\begin{array}{cccc}(8.085)^{* *} & (8.867)^{* *} & (9.975)^{* *} & (10.94)^{* *}\end{array}$

$\begin{array}{llll}35.77 & 37.71 & 43.18 & 45.52\end{array}$

$\begin{array}{cccc}(14.94)^{* *} & (15.75)^{* *} & (18.43)^{* *} & (19.43)^{* *}\end{array}$

(10)

75th Percentile of the WTP Distribution

$\begin{array}{cc} & \text { Add Controls and } \\ \text { Body Type x Model } & \text { Model and Body } \\ \text { Year \& Model Year } & \text { Type x Model Year }\end{array}$

Year \& Model Year ${ }^{2}$

Type x Model Y

odel Year

Blue NADA Blue NADA

Book Book

$\$ 8,117 \quad \$ 2,407 \quad \$ 4,107 \quad \$ 1,881$

$\begin{array}{llll}(1,775)^{* *} & (852.3)^{* *} & (2,841) & (574.1)^{* *}\end{array}$

Notes to Table 6: In row 1, Columns (1) to (4) show the premium on a driver's side air bag for an observation year in which 75\% of registered vehicles had driver's side air bags. Row 2 shows the risk reduction over the remaining years of the average vehicle's life for a vehicle with an air bag in that observation year (assuming a constant risk reduction per vehicle year). Row 3 divides row 1 by row 2 to estimate the 25 ${ }^{\text {th }}$ percentile of the VSL distribution. Columns (5) to (8) estimate the same parameters for the year in which $50 \%$ of vehicles had air bags, and columns (9) to (12) estimate the parameters for the year in which $25 \%$ of vehicles had air bags. Panel A shows estimates for driver's side air bags, and panel B shows estimates for passenger's side air bags. The specifications in columns (1), (2), (5), (6), (9), and (10) are the same as in panels A and B of Figure 4. The specifications in columns (3), (4), (7), (8), (11), and (12) are the same as in panels $\mathrm{C}$ and $\mathrm{D}$ of Figure 4 . Additional details in the text. 
Table 7: Sensitivity Analysis of VSL at the 50th Percentile Under Alternative Specifications

\begin{tabular}{|c|c|c|c|c|c|c|c|c|c|}
\hline & & (1) & (2) & (3) & (4) & (5) & (6) & (7) & (8) \\
\hline & & \multicolumn{4}{|c|}{ Driver's Side } & \multicolumn{4}{|c|}{ Passenger's Side } \\
\hline & & \multicolumn{2}{|c|}{ No Fixed Effects } & \multicolumn{2}{|c|}{$\begin{array}{l}\text { Add Model x } \\
\text { Observation Year } \\
\text { Fixed Effects }\end{array}$} & \multicolumn{2}{|c|}{ No Fixed Effects } & \multicolumn{2}{|c|}{$\begin{array}{c}\text { Add Model x } \\
\text { Observation Year Fixed } \\
\text { Effects }\end{array}$} \\
\hline & & $\begin{array}{l}\text { Kelley } \\
\text { Blue } \\
\text { Book }\end{array}$ & NADA & $\begin{array}{l}\text { Kelley } \\
\text { Blue } \\
\text { Book }\end{array}$ & NADA & $\begin{array}{l}\text { Kelley } \\
\text { Blue } \\
\text { Book }\end{array}$ & NADA & $\begin{array}{l}\text { Kelley } \\
\text { Blue } \\
\text { Book }\end{array}$ & NADA \\
\hline 1. & $\begin{array}{l}\text { Benchmark } \\
\text { Estimates }\end{array}$ & $\begin{array}{c}\$ 12.96 \\
(3.582)^{* *}\end{array}$ & $\begin{array}{c}\$ 6.557 \\
(2.855)^{* *}\end{array}$ & $\begin{array}{l}\$ 10.79 \\
(10.51)\end{array}$ & $\begin{array}{c}\$ 8.926 \\
(5.251)^{*}\end{array}$ & $\begin{array}{c}\$ 110.7 \\
(49.61)^{* *}\end{array}$ & $\begin{array}{c}\$ 114.7 \\
(51.83)^{* *}\end{array}$ & $\begin{array}{l}\$ 15.02 \\
(17.10)\end{array}$ & $\begin{array}{c}\$ 28.20 \\
(14.86)^{*}\end{array}$ \\
\hline 2. & $\begin{array}{l}\text { Assuming } \\
13 \% \text { Fatality } \\
\text { Effect }\end{array}$ & $\begin{array}{c}\$ 3.331 \\
(0.835)^{* *}\end{array}$ & $\begin{array}{c}\$ 1.686 \\
(0.703)^{* *}\end{array}$ & $\begin{array}{l}\$ 1.310 \\
(1.074)\end{array}$ & $\begin{array}{c}\$ 1.084 \\
(0.286)^{* *}\end{array}$ & $\begin{array}{c}\$ 4.446 \\
(0.998)^{* *}\end{array}$ & $\begin{array}{c}\$ 2.024 \\
(0.716)^{* *}\end{array}$ & $\begin{array}{l}\$ 2.249 \\
(1.556)\end{array}$ & $\begin{array}{c}\$ 1.582 \\
(0.483)^{* *}\end{array}$ \\
\hline 3. & $\begin{array}{l}\text { Log } \\
\text { Specification } \\
\text { for Price }\end{array}$ & $\begin{array}{c}\$ 4.340 \\
(2.565)^{*}\end{array}$ & $\begin{array}{l}\$ 3.696 \\
(7.367)\end{array}$ & $\begin{array}{l}-\$ 5.847 \\
(3.436)\end{array}$ & $\begin{array}{c}\$ 5.062 \\
(2.687)^{*}\end{array}$ & $\begin{array}{c}\$ 63.28 \\
(29.40)^{* *}\end{array}$ & $\begin{array}{c}\$ 82.20 \\
(37.88)^{* *}\end{array}$ & $\begin{array}{l}-\$ 18.73 \\
(17.10)\end{array}$ & $\begin{array}{l}\$ 4.208 \\
(7.234)\end{array}$ \\
\hline 4. & $\begin{array}{l}\text { Log } \\
\text { Specification } \\
\text { for Fatalities }\end{array}$ & $\begin{array}{c}\$ 1.665 \\
(0.843)^{* *}\end{array}$ & $\begin{array}{l}\$ 1.428 \\
(1.181)\end{array}$ & $\begin{array}{c}\$ 2.222 \\
(1.011)^{* *}\end{array}$ & $\begin{array}{c}\$ 1.011 \\
(0.392)^{* *}\end{array}$ & $\begin{array}{c}\$ 42.93 \\
(18.52)^{* *}\end{array}$ & $\begin{array}{c}\$ 33.94 \\
(16.35)^{* *}\end{array}$ & $\begin{array}{l}-\$ 0.834 \\
(5.680)\end{array}$ & $\begin{array}{l}-\$ 4.166 \\
(7.249)\end{array}$ \\
\hline 5. & $\begin{array}{l}\text { Adjusted for } \\
\text { Quantity } \\
\text { Change }\end{array}$ & $\begin{array}{c}\$ 11.69 \\
(4.019)^{* *}\end{array}$ & $\begin{array}{c}\$ 6.665 \\
(2.923)^{* *}\end{array}$ & $\begin{array}{l}\$ 7.843 \\
(12.18)\end{array}$ & $\begin{array}{c}\$ 10.84 \\
(6.440)^{*}\end{array}$ & $\begin{array}{c}\$ 111.1 \\
(50.15)^{* *}\end{array}$ & $\begin{array}{c}\$ 115.2 \\
(52.30)^{* *}\end{array}$ & $\begin{array}{l}\$ 25.71 \\
(19.75)\end{array}$ & $\begin{array}{c}\$ 38.33 \\
(18.98)^{* *}\end{array}$ \\
\hline 6. & $\begin{array}{c}\text { SUVs } \\
\text { Excluded }\end{array}$ & $\begin{array}{c}\$ 24.99 \\
(5.004)^{* *}\end{array}$ & $\begin{array}{c}\$ 14.03 \\
(2.914)^{* *}\end{array}$ & $\begin{array}{l}-\$ 19.55 \\
(13.11)\end{array}$ & $\begin{array}{l}-\$ 0.353 \\
(3.314)\end{array}$ & $\begin{array}{c}\$ 74.11 \\
(24.19)^{* *}\end{array}$ & $\begin{array}{c}\$ 52.94 \\
(15.46)^{* *}\end{array}$ & $\begin{array}{l}\$ 1.892 \\
(20.14)\end{array}$ & $\begin{array}{c}\$ 15.37 \\
(6.661)^{* *}\end{array}$ \\
\hline
\end{tabular}

Notes to Table 7: Each row shows a different set of estimates of the implied VSL at the $50^{\text {th }}$ percentile of the distribution. Row 1 shows the benchmark estimates, which also appear in rows 3 and 6, columns (4) to (8) of Table 6. Row 2 supposes that air bags reduce auto-related fatalities by $13 \%$, as publicized in the media. Row 3 estimates the marginal effect of air bags on prices using a regression with the natural log of price as the dependent variable. Row 4 estimates the marginal effect of air bags on fatalities using a regression with the natural log of the fatality rate as a dependent variable. Row 5 estimates the willingness to pay for an air bag as the price effect minus 1,000/0.661 times the effect of an air bag on $\ln$ (volume traded), where -0.661 is the estimated effect of a $\$ 1,000$ subsidy on $\log$ of automobile demand. Row 6 excludes SUVs from the sample. Additional details in the text; the quantity correction for row 5 is described in the appendix. 
Figure 1: Fraction of Vehicles with Air Bags by Model Year and Observation Year

Panel A: Fraction of Vehicles with Air Bags by Model Year

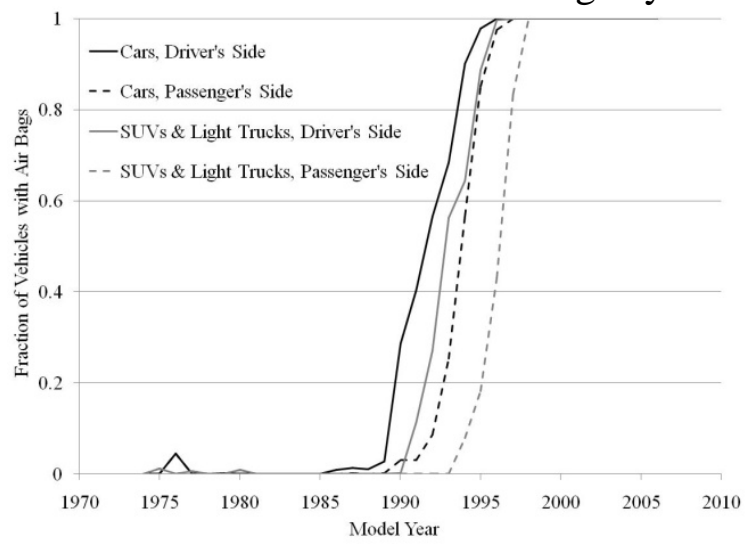

Panel B: Fraction of New and Used Vehicles with Air Bags by Year Purchased

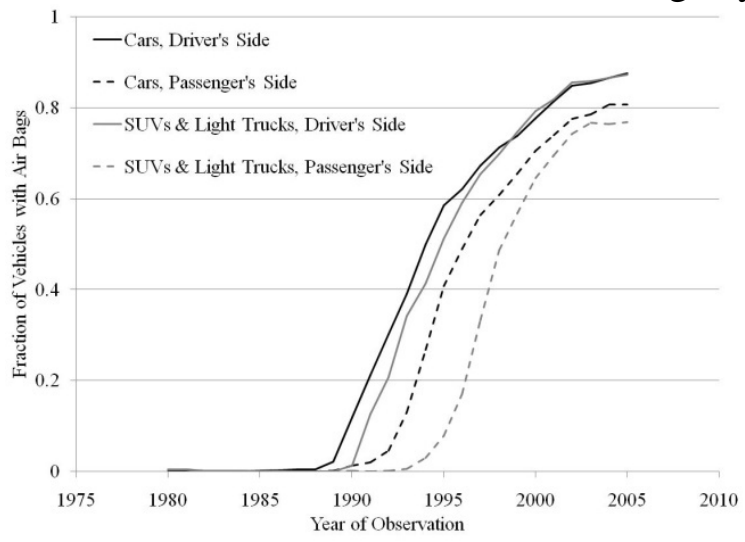

Panel C: Fraction of Vehicles with Air Bags by Observation Year

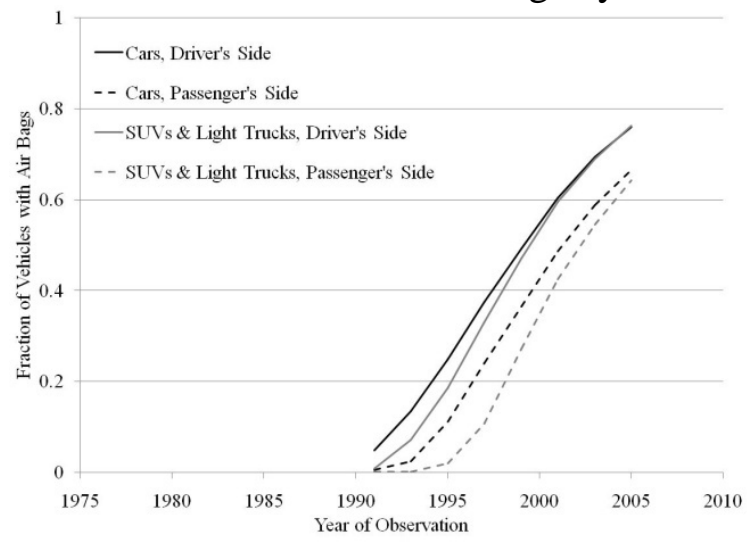

Notes to Figure 1: Air bag and vehicle type data taken from 1990-2003 NCAP and 1975-2006 FARS. Numbers of vehicles by purchase year taken from 1984-2005 CEX. Numbers of registered vehicles by model taken from 1991-2005 NVPP (biennial). In panels A and C, each model x model year combination is weighted by the number of registered vehicles of that type in the NVPP, where the weights in panel A are summed across available years. In panel $\mathrm{B}$, each model $\mathrm{x}$ model year is weighted by the number of vehicles of that type purchased in that year by a CEX respondent (with CEX weights). Additional details in the text. 
Figure 2: Illustration of Estimation Strategy

\section{Panel A: Supply and Demand for Air Bags over Time}

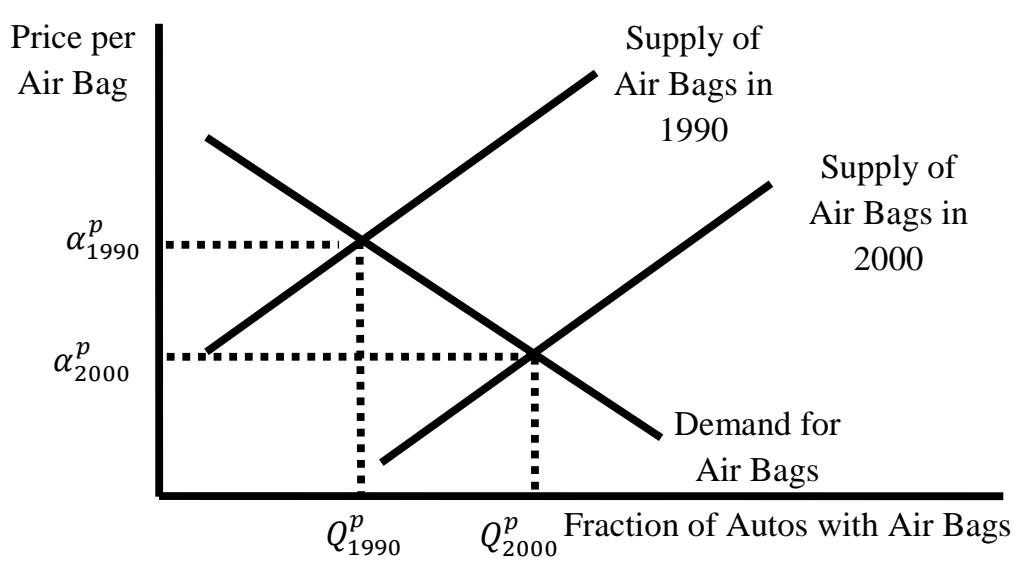

Panel B: Illustration of the Demand for Fatality Reductions and the Distribution of the VSL

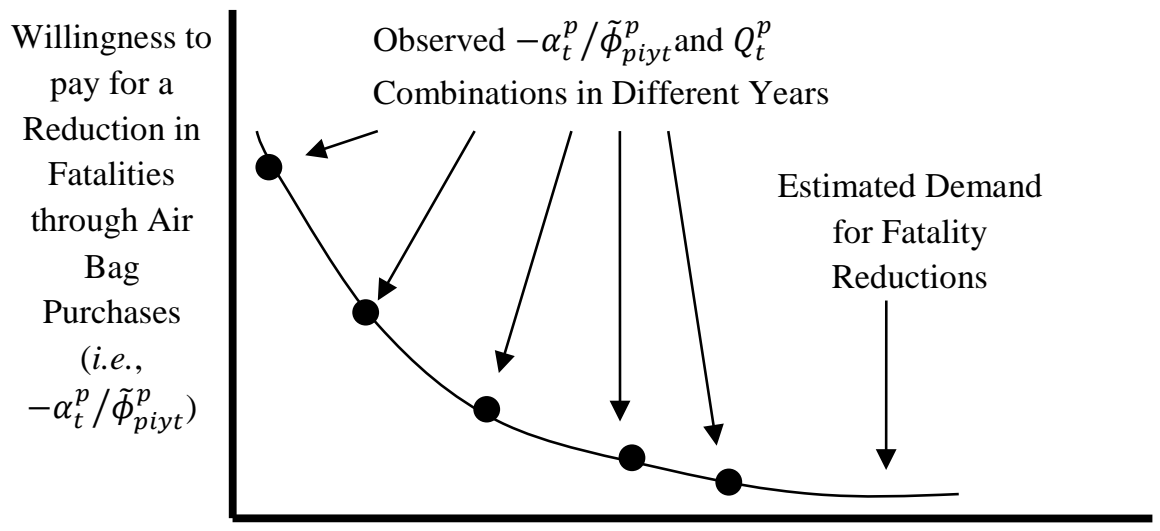

Fraction of Autos with Air Bags 


\section{Panel A: Driver's Side Air Bags} and Fatalities

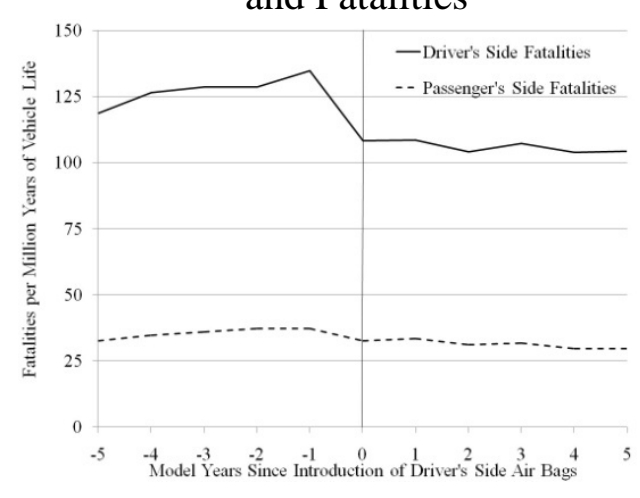

Panel C: Driver's Side Air Bags and Auto Prices

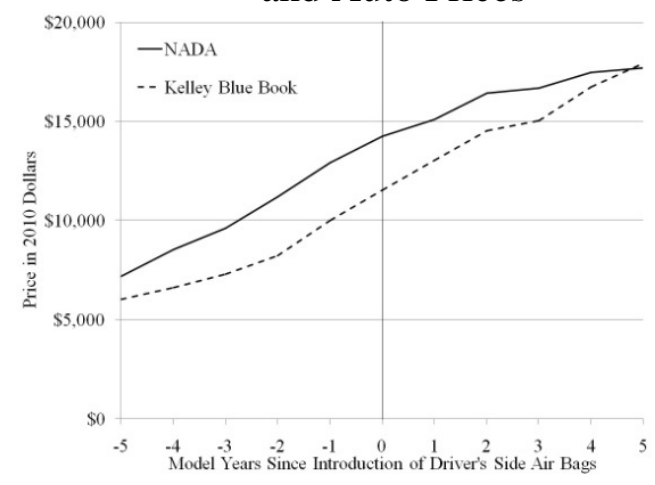

Panel E: Driver's Side Air Bags and Quantity Demanded

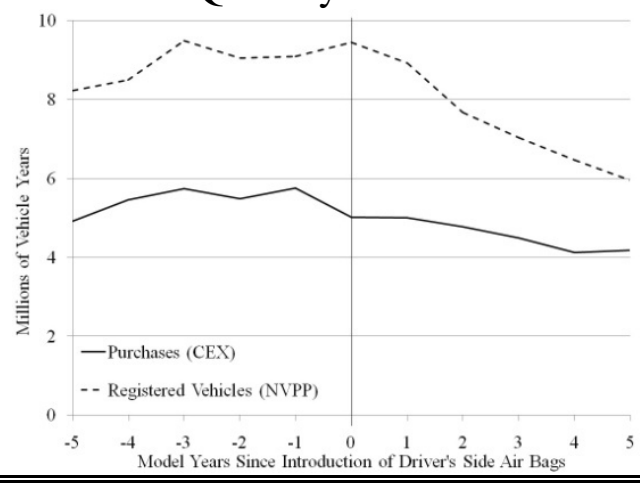

\section{Panel B: Passenger’s Side Air Bags} and Fatalities

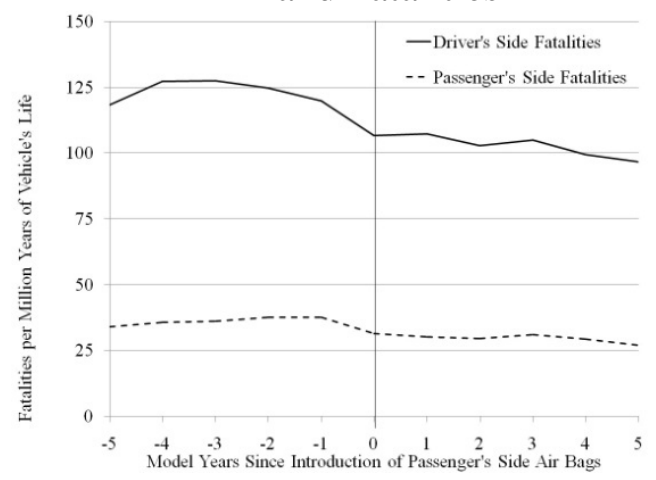

Panel D: Passenger’s Side Air Bags and Auto Prices

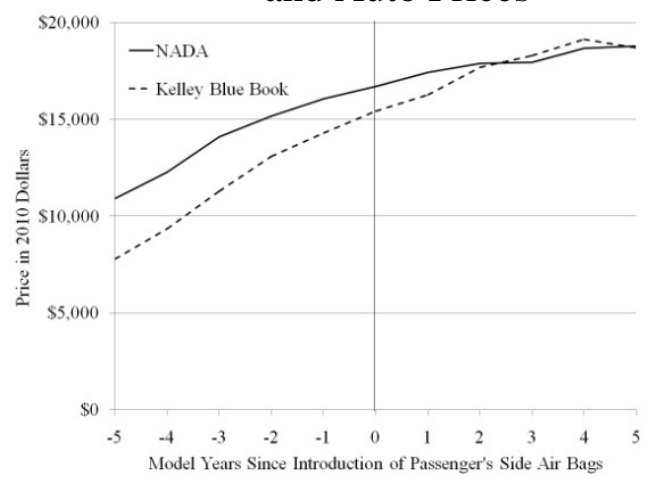

Panel F: Passenger’s Side Air Bags and Quantity Demanded

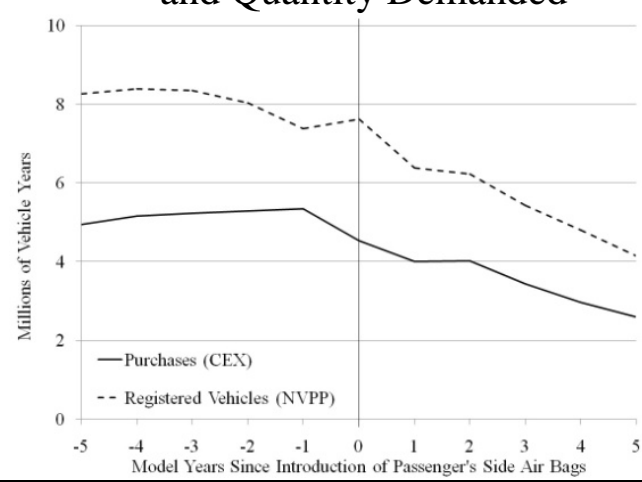

Notes to Figure 3: Fatalities data come from FARS, 1984-2006. Price data come from NADA 1993-2005 and Kelley Blue Book, 1997-2005. Fatalities are weighted by numbers of registered vehicles of that model and model year in the NVPP that year; because biennial NVPP data are used, in between years are imputed by linear interpolation. Price data are weighted by the number of buyers of each vehicle in different years, summed across available years. All variables are averaged across available observation years. Data sources and samples are the same as in Table 1. 
Figure 4: Effects of Air Bags on Prices over Time

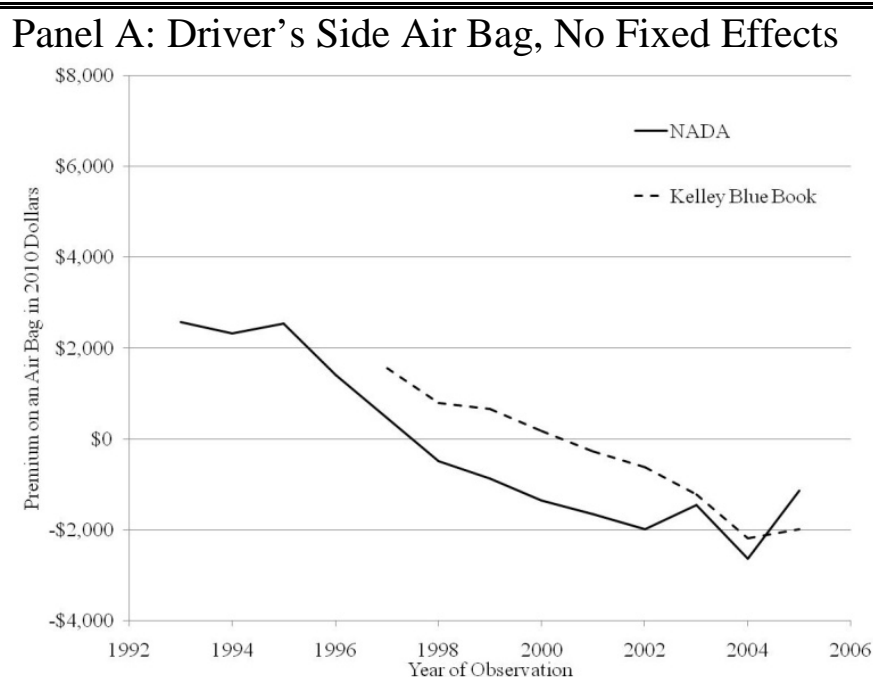

Panel C: Driver's Side, Fixed Effects \& Controls

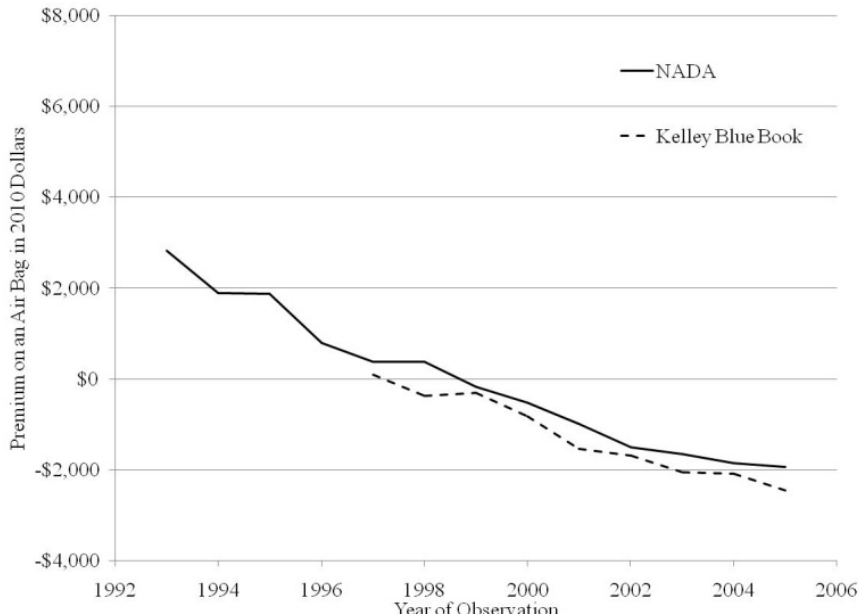

Panel B: Passenger’s Side Air Bag, No Fixed Effects

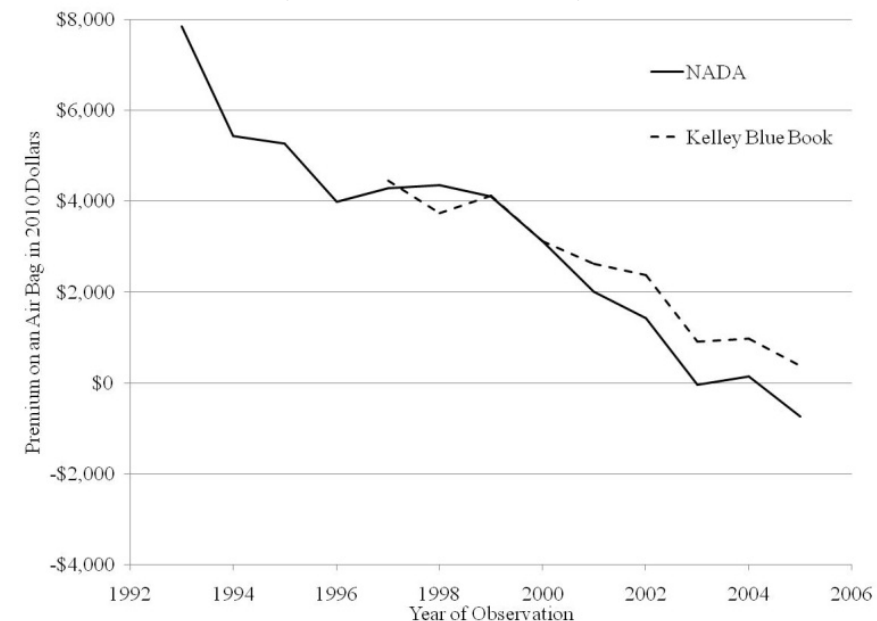

Panel D: Passenger's Side, Fixed Effects \& Controls

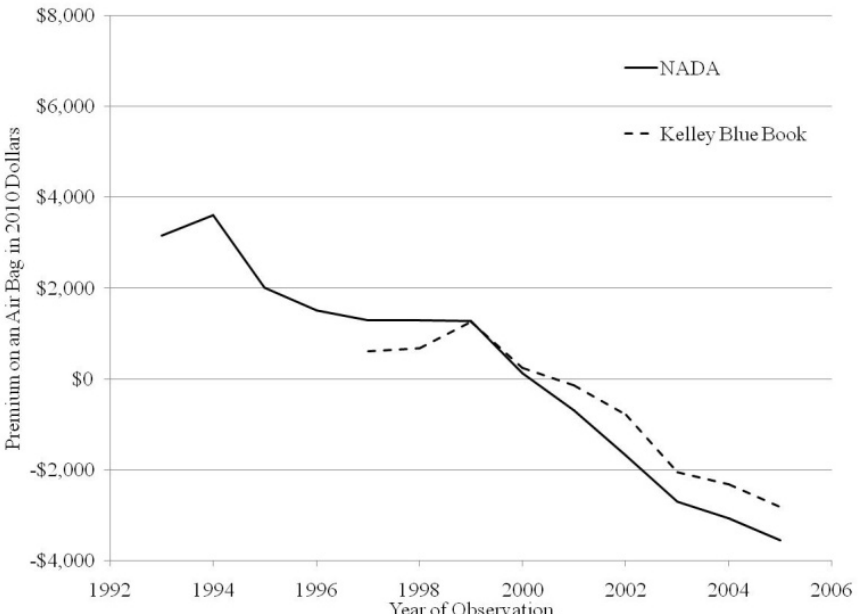

Notes to Figure 4: Each graph shows the coefficients on air bag (driver's or passenger's side) interacted with each year of observation in the data. The specifications in panels A and B use the discontinuity sample and control for quadratics in model year and observation year, as in columns (4) and (10) of Tables 5 and 6. Panels $C$ and D add auto attribute controls and model by observation year and model year by body type interactions, as in columns (6) and (12) of Table 5. Additional details in the text. 
Figure 5: Estimated CDF of the VSL by Race and Age Category

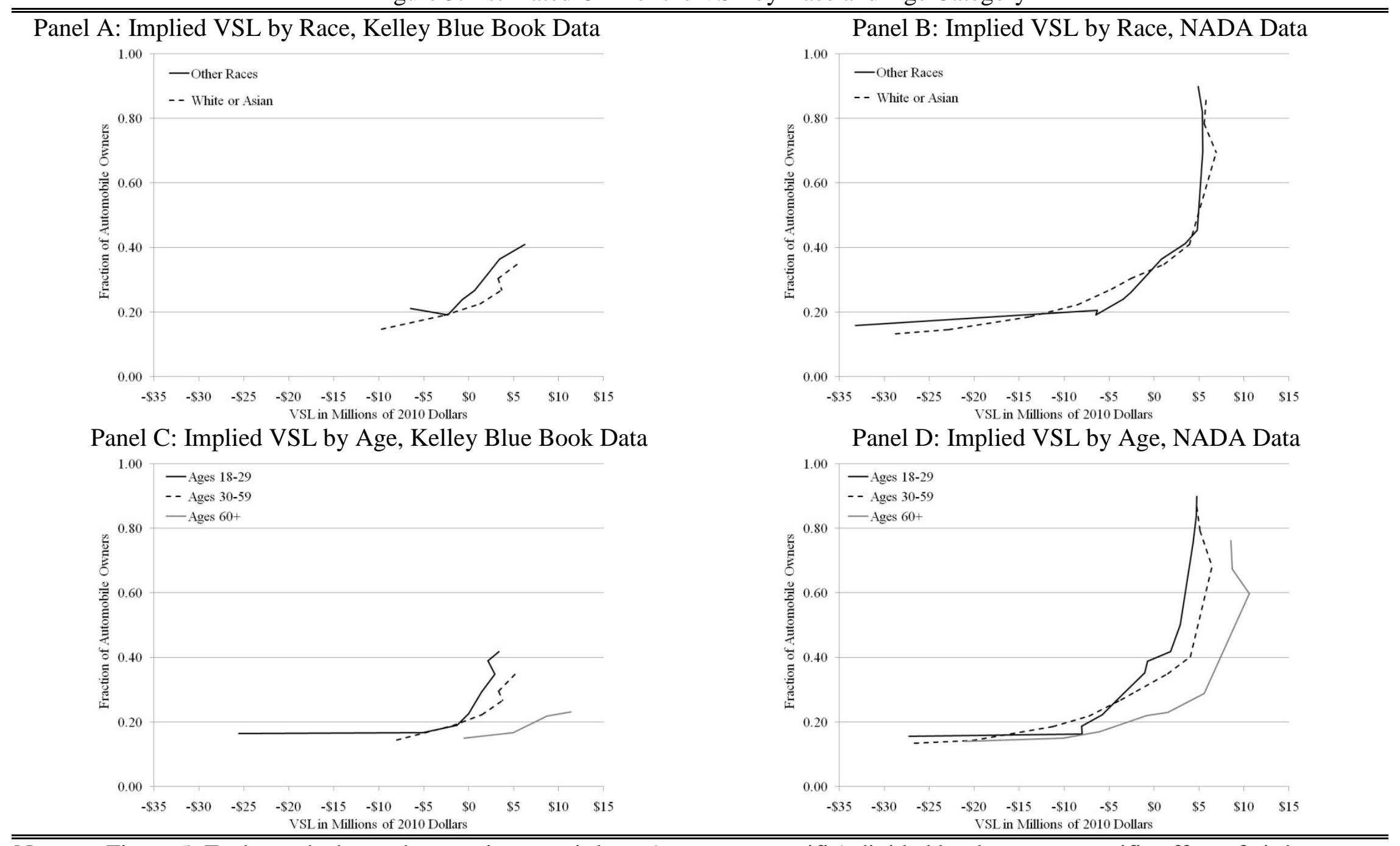

Notes to Figure 5: Each graph shows the premium on air bags (not group specific) divided by the group-specific effect of air bags on fatalities, plotted against the group-specific fraction of automobile owners with air bags in different observation years. The premium on driver's side air bags and the specification without model fixed effects is used, as in columns (1), (2), (5), (6), (9), and (10) of panel A of Table 6. 
Figure 6: Median VSL versus Median Household Income by State

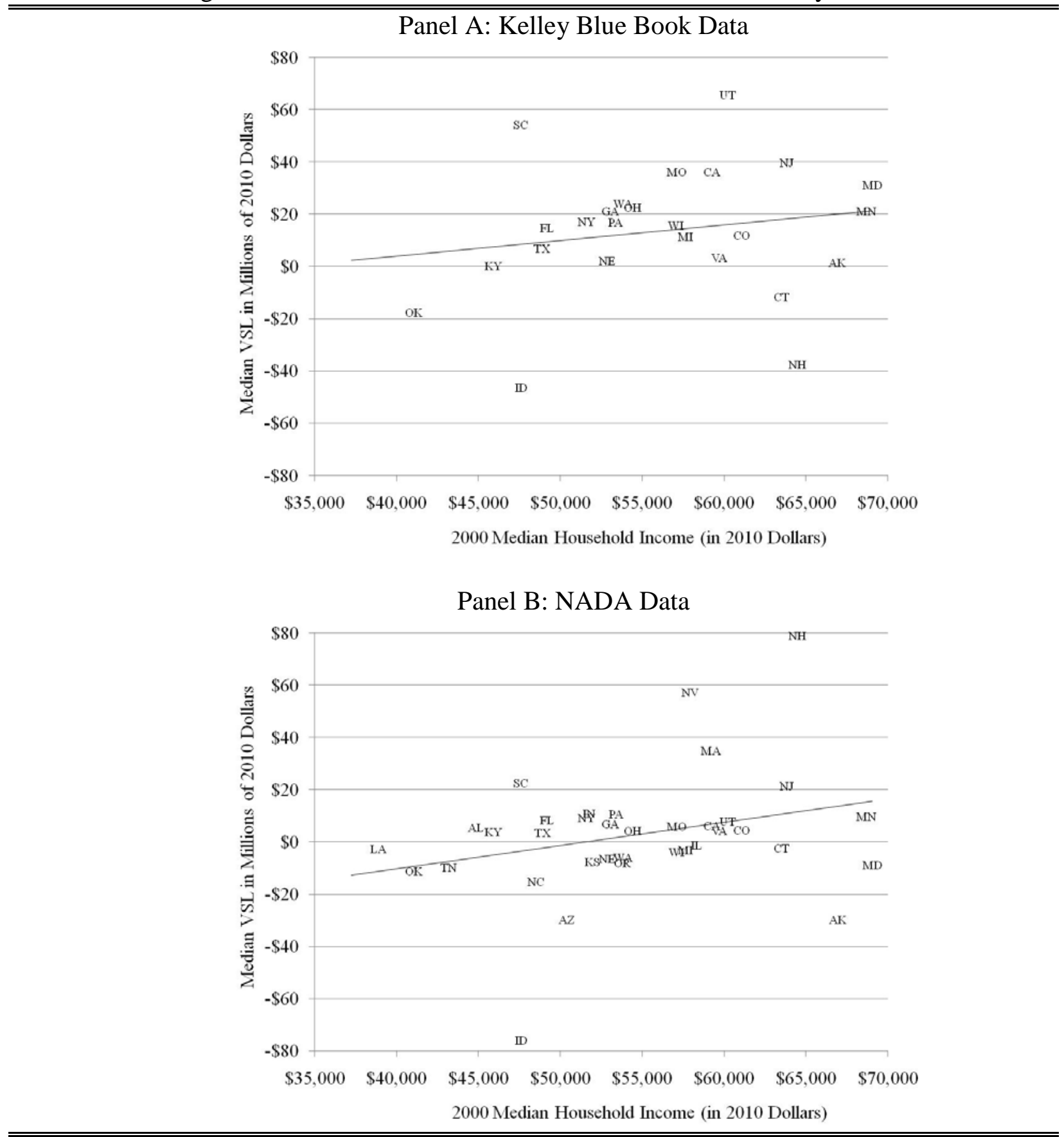

Notes to Figure 6: Median VSL estimates are constructed in the same way as in Table 6, but with state-specific data used for automobile quantities (from the CEX) and region-specific data and regressions used for Kelley Blue Book prices and fatalities. The driver's side estimates with no fixed effects are used. The Kelley Blue Book data track prices in three regions, Northeast (including Ohio), Midwest and South, and West; nation-level price data are used for the NADA graph. Both price regressions are weighted by state-specific numbers of registered vehicles by make, model, model year, and year. The state-level fatalities data are collapsed into four Census regions. Median household income in 2000 by state is taken from U.S. Census Bureau (2009). Additional details in the text. 


\section{Appendix}

\section{$\underline{\text { A. Measurement of Air Bag and Automatic Seat Belt Variables }}$}

The air bags and automatic seatbelt variables used in this study were constructed from NCAP and FARS variables. The NCAP data measure air bag availability as part of their assessments of all new vehicles. The FARS data include police reports of air bag presence and deployment in each vehicle. For vehicles that did not have air bags, the 1975-1990 FARS data also include information on the presence of automatic seatbelts. Only 69 make, model, and model year combinations were observed with automatic seatbelts in the data. All three variables were averaged across observations with the same make, model, and model year and rounded to zero or one. Some models in the data are grouped together and it is possible that some of those models had air bags while others did not, in which cases rounding would be inappropriate. Nevertheless, typos were identified in each of the datasets. Rounding the FARS air bag measures increased their correlation with the unrounded NCAP measures, and rounding the NCAP measures increased their correlation with the unrounded FARS measures.

In addition to rounding, all three variables were edited to ensure consistency with the regulations (which all manufacturers met) and to pass certain logical conditions. Each model was assumed to adopt driver's side air bags in a single model year and to adopt passenger's side air bags in a single model year; these two years could be the same. The vehicle is assumed to have air bags in every model year after the first model year in which an air bag was observed. Any vehicle with a passenger's side air bag is assumed to have had a driver’s side air bag. Any vehicle produced in 1990 or later without a driver's side air bag is assumed to have an automatic seatbelt. Any vehicle with an automatic belt is assumed to have had one for a continuous set of years (no gaps in availability). Any passenger car, or light truck or SUV produced on or after its 
1996, 1997, and 1998 deadlines for air bag availability is assumed to have the relevant air bag. Any vehicle with a driver's side air bag is assumed not to have an automatic belt, with the exceptions of the 1995-1996 Ford Escorts and Mercury Tracers, which are reported to have both (Wikipedia, 2011). ${ }^{17}$ Any vehicle produced prior to 1990 and not observed in the FARS data as having an automatic belt is assumed not to have one.

To evaluate measurement error in the air bags variables, correlation matrices between the NCAP and FARS drivers' and passengers' side air bag measures are shown in Table A1. Panel A shows the correlations for the full sample with no controls. Panel B shows the correlations after adjusting for model and body type by model year fixed effects. Panel C shows the correlations after for the +/- 2 discontinuity sample with no controls, and panel D shows the correlations using the discontinuity sample with the fixed effects. In all four cases, the NCAP and FARS variables are highly correlated for both the driver's and the passenger's side bags. In the full sample with no controls, the correlations are 0.861 and 0.957 . After adjusting for the fixed effects, these correlations drop to 0.745 and 0.816 , a result that suggests that, when fixed effects are included, the measurement error is nontrivial but is not severe. Similar results are obtained using the discontinuity sample, with correlations of 0.846 and 0.924 without controls and 0.807 and 0.779 with the fixed effects. Hence, the use of the discontinuity sample does not substantially exacerbate the measurement error.

The final air bags variables used in the analysis are taken from the NCAP when NCAP data are available and the FARS data when the NCAP data are not available. A single measure is used rather than an instrumental variables approach because the NCAP data are only available for a limited number of observations.

\footnotetext{
${ }^{17}$ The Wikipedia article also states that the AMC Eagle Summit Wagon had both air bags and automatic belts; however, this vehicle is grouped together in the data with other AMC Eagle vehicles that did not have the feature, and the Summit Wagon is a relatively small fraction of the overall number of models in that category.
} 


\section{B. Effects of Air Bags on Quantity Demanded}

A typical quasi-experimental hedonic analysis supposes that the quantity supplied is fixed, so that all of the benefits of the amenity shock are capitalized into the price of the good. Figure A1, adapted from Bartik (1987) and Rohlfs (2011b, illustrates a setting in which supply is somewhat elastic, and the effect of air bags on prices understate MWTP. In the figure, the suppliers of used automobiles respond to the high demand for vehicles with air bags by selling them at greater rates than they would vehicles without air bags. Line 5 in the sensitivity analysis in Table 7 performs a correction to the median VSL estimates to adjust for this quantity response. The adjustment is calculated following Rohlfs (2011a, 2011b) and involves taking the price response and adding the quantity response multiplied by negative one times the slope of the demand response for cars. The slope of the demand response for cars is estimated as $-0.661 \log$ points per \$1,000 using data from Sallee (2011) on the effect of the hybrid tax break on demand for the Toyota Prius. ${ }^{18}$ The estimates presented in Table 7 do not account for imprecision in this estimated demand effect. In practice, the effects of air bags on trading volumes are large and negative in the earliest years of the data (when air bags were rare), but are insignificant and close to zero for most of the years in the data (estimates not shown).

\footnotetext{
${ }^{18}$ Sallee examines the effect on prices but provides quantity data in the tables. This -0.661 estimate is the average across the estimated quantity responses to three different tax changes.
} 


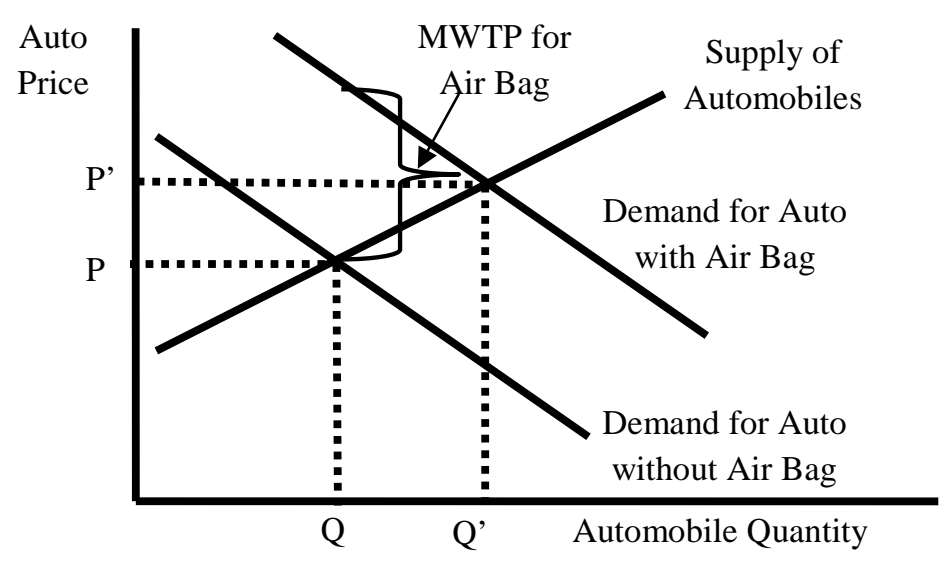


Table A1: Correlations Between NCAP and FARS Measures of Air Bag Availability

Panel A: Full Sample, No Controls

\begin{tabular}{|c|c|c|c|c|c|c|c|c|}
\hline & $\begin{array}{c}\text { NCAP } \\
\text { Driver's } \\
\text { Side }\end{array}$ & $\begin{array}{l}\text { FARS } \\
\text { Driver's } \\
\text { Side }\end{array}$ & $\begin{array}{l}\text { NCAP } \\
\text { Passenger's } \\
\text { Side }\end{array}$ & $\begin{array}{l}\text { FARS } \\
\text { Passenger's } \\
\text { Side }\end{array}$ & $\begin{array}{c}\text { NCAP } \\
\text { Driver's } \\
\text { Side }\end{array}$ & $\begin{array}{c}\text { FARS } \\
\text { Driver's } \\
\text { Side }\end{array}$ & $\begin{array}{l}\text { NCAP } \\
\text { Passenger's } \\
\text { Side }\end{array}$ & $\begin{array}{c}\text { FARS } \\
\text { Passenger's } \\
\text { Side }\end{array}$ \\
\hline NCAP Driver's Side & 1.0000 & & & & 1.0000 & & & \\
\hline FARS Driver's Side & 0.8609 & 1.0000 & & & 0.7448 & 1.0000 & & \\
\hline NCAP Passenger's Side & 0.6060 & 0.6951 & 1.0000 & & 0.2147 & 0.2535 & 1.0000 & \\
\hline FARS Passenger's Side & 0.5894 & 0.6831 & 0.9567 & 1.0000 & 0.1410 & 0.1915 & 0.8160 & 1.0000 \\
\hline \multicolumn{5}{|c|}{ Panel C: +/-2 Discontinuity Sample, No Controls } & \multicolumn{4}{|c|}{$\begin{array}{l}\text { Panel D: +/-2 Discontinuity Sample, Adjusting for } \\
\text { Model and Body Type x Model Year Fixed Effects }\end{array}$} \\
\hline NCAP Driver's Side & 1.0000 & & & & 1.0000 & & & \\
\hline FARS Driver's Side & 0.8462 & 1.0000 & & & 0.8070 & 1.0000 & & \\
\hline NCAP Passenger's Side & 0.4744 & 0.5152 & 1.0000 & & 0.2933 & 0.3091 & 1.0000 & \\
\hline FARS Passenger's Side & 0.4247 & 0.4980 & 0.9244 & 1.0000 & 0.2034 & 0.2540 & 0.7788 & 1.0000 \\
\hline Observations & \multicolumn{4}{|c|}{2,385} & \multicolumn{4}{|c|}{318} \\
\hline Models & \multicolumn{4}{|c|}{348} & \multicolumn{4}{|c|}{73} \\
\hline
\end{tabular}

Notes to Table A1: Each panel shows a matrix of correlations between the NCAP and FARS driver's and passenger's side air bag measures. Observations are weighted by the NVPP counts of registered vehicles, summed across available years. Additional details in the text.

Panel B: Full Sample, Adjusting for Model and Body Type x Model Year Fixed Effects

Panel D: +/-2 Discontinuity Sample, Adjusting for Model and Body Type x Model Year Fixed Effects 